\title{
Conjunctivitis: A Systematic Review
}

\author{
Amir A. Azari, $\mathrm{MD}^{1,2}$, Amir Arabi, MD, $\mathrm{MPH}^{1,2}$ \\ ${ }^{1}$ Ophthalmic Research Center, Research Institute for Ophthalmology and Vision Science, Shahid Beheshti University of Medical \\ Sciences, Tehran, Iran \\ ${ }^{2}$ Department of Ophthalmology, Torfeh Medical Center, Shahid Beheshti University of Medical Sciences, Tehran, Iran \\ ORCID: \\ Amir A. Azari: https://orcid.org/0000-0003-2013-3284
}

\section{Abstract}

Conjunctivitis is a commonly encountered condition in ophthalmology clinics throughout the world. In the management of suspected cases of conjunctivitis, alarming signs for more serious intraocular conditions, such as severe pain, decreased vision, and painful pupillary reaction, must be considered. Additionally, a thorough medical and ophthalmic history should be obtained and a thorough physical examination should be done in patients with atypical findings and chronic course. Concurrent physical exam findings with relevant history may reveal the presence of a systemic condition with involvement of the conjunctiva. Viral conjunctivitis remains to be the most common overall cause of conjunctivitis. Bacterial conjunctivitis is encountered less frequently and it is the second most common cause of infectious conjunctivitis. Allergic conjunctivitis is encountered in nearly half of the population and the findings include itching, mucoid discharge, chemosis, and eyelid edema. Long-term usage of eye drops with preservatives in a patient with conjunctival irritation and discharge points to the toxic conjunctivitis as the underlying etiology. Effective management of conjunctivitis includes timely diagnosis, appropriate differentiation of the various etiologies, and appropriate treatment.

Keywords: Allergic; Bacterial; Conjunctivitis; COVID-19; Coronavirus; Viral; Toxic

J Ophthalmic Vis Res 2020; 15 (3): 372-395

\section{INTRODUCTION}

Conjunctivitis is characterized by inflammation and swelling of the conjunctival tissue, accompanied

Correspondence to:

Amir A. Azari, MD. Ophthalmic Research Center, Research Institute for Ophthalmology and Vision Science, Shahid Beheshti University of Medical Sciences, No. 23, Paidarfdard St., Boostan 9 St., Pasadaran Ave., Tehran 16666, Iran.

Email: amirazarimd@gmail.com

Received: 18-02-2020 Accepted: 25-04-2020

\section{Access this article online}

Website: https://knepublishing.com/index.php/JOVR

DOI: $10.18502 /$ jovr.v15i3.7456 by engorgement of the blood vessels, ocular discharge, and pain. Many subjects are affected with conjunctivitis worldwide, and it is one of the most frequent reasons for office visits to general medical and ophthalmology clinics. More than $80 \%$ of all acute cases of conjunctivitis are reported to be diagnosed by non-ophthalmologists including internists, family medicine physicians,

This is an open access journal, and articles are distributed under the terms of the Creative Commons Attribution-NonCommercial-ShareAlike 4.0 License, which allows others to remix, tweak, and build upon the work non-commercially, as long as appropriate credit is given and the new creations are licensed under the identical terms.

How to cite this article: Azari AA Arabi A. Conjunctivitis: A Systematic Review. J Ophthalmic Vis Res 2020;15:372-395. 
pediatricians, and nurse practitioners. $^{[1]}$ This imposes a great economic burden to the healthcare system and occupies a great proportion of the office visits in many medical specialties. It is estimated that the cost of treating bacterial conjunctivitis is $\$ 857$ million annually in the United States alone. $^{[2]}$

It has been reported that nearly $60 \%$ of all patients with acute conjunctivitis receive antibiotic eye drops; and the vast majority receive their prescription from a non-ophthalmologist physician. For example, $68 \%$ of patients who visited a physician at an emergency room received antibiotic eye drops while this figure dropped to $36 \%$ for those who saw an ophthalmologist. $^{[1]}$ Interestingly, patients from a higher socioeconomic status were more likely to receive and fill a prescription for their

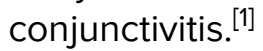

There are several ways to categorize conjunctivitis; it may be classified based on etiology, chronicity, severity, and extend of involvement of the surrounding tissue. The etiology of conjunctivitis may be infectious or non-infectious. Viral conjunctivitis followed by bacterial conjunctivitis is the most common cause of infectious conjunctivitis, while allergic and toxin-induced conjunctivitis are among the most common non-infectious etiologies. In terms of chronicity, conjunctivitis may be divided into acute with rapid onset and duration of four weeks or less, subacute, and chronic with duration longer than four weeks. ${ }^{[3]}$ Furthermore, conjunctivitis may be labeled as severe when the affected individuals are extremely symptomatic and there is an abundance of mucopurulent discharge. Conjunctivitis may be associated with the involvement of the surrounding tissue such as the eyelid margins and cornea in blepharoconjunctivitis and viral keratoconjunctivitis, respectively.

Additionally, conjunctivitis may be associated with systemic conditions, including immunerelated diseases [e.g., Reiter's, Stevens-Johnson syndrome (SJS), and keratoconjunctivitis sicca in rheumatoid arthritis], nutritional deprivation (vitamin A deficiency), and congenital metabolic syndromes (RichnerHanhart syndrome and porphyria) ${ }^{[4,5]}$ (Table 1).
It is extremely important to differentiate conjunctivitis from other causes of "red eye" associated with severe sight- or life-threatening consequences such as acute angle closure glaucoma, uveitis, endophthalmitis, carotidcavernous fistula, cellulitis, and anterior segment tumors.

\section{METHODS}

The scientific literature published as of February 2020 was thoroughly reviewed by searching PubMed, the ISI web of knowledge database, and the Cochrane library using relevant keywords. The following keywords were used: "bacterial conjunctivitis", "viral conjunctivitis," "allergic conjunctivitis", "treatment of bacterial conjunctivitis", and "treatment of viral conjunctivitis". No language restriction was applied.

Articles published between March 2013 and February 2020 were screened and those that provided the best evidence-based information were included in this review. A total of 167 articles were finally included. The first study was published in 1964 and the last study was published in 2020.

\section{History and clinical examination}

\section{How to diagnose conjunctivitis}

Conjunctival injection or "red eye" is a shared presentation for many ophthalmic diseases, and it accounts for up to $1 \%$ of all primary care office visits. ${ }^{[6]}$ The clinicians, whether ophthalmologist or not, must be aware that "red eye" may be the presenting sign for serious eye conditions such as uveitis, keratitis, or scleritis, or it may be secondary to more benign conditions that are limited just to the conjunctival tissue (e.g., conjunctivitis or subconjunctival hemorrhage). Traditionally, it was believed that more harmful ophthalmic disorders are associated with disturbances in vision, disabling pain, and photophobia. ${ }^{[6]}$ However, in a recent large metaanalysis, ${ }^{[6]}$ anisocoria and mild photophobia were significantly associated with "serious eye conditions"; the presence of these two signs could discover $59 \%$ of cases of "serious eye conditions", including anterior uveitis and keratitis. Table 2 provides a summary of the 
Table 1. Guideline to help differentiate the major etiologies in conjunctivitis

Clinical history and exam findings

Most probable etiologies

Alarming signs and symptoms

Decreased vision, severe pain, painful pupillary reaction, anisocoria, orbital signs

Sudden onset, lasting less than four weeks

Insidious onset, chronic course

Recurrent course

Skin lesions, arthropathy, genito-perineal involvement, oropharyngeal lesions

Recent initiation of a systemic medication
Long-term eye drop usage

Uveitis, scleritis, keratitis, glaucoma, orbital, or parasellar pathology

\section{Chronicity}

Infectious conjunctivitis, allergic conjunctivitis, acute systemic reactions (SJS/TEN)

Conjunctivitis associated with systemic diseases, toxic conjunctivitis, allergic conjunctivitis

Allergic conjunctivitis, conjunctivitis associated with systemic diseases

\section{Associated symptoms}

SJS, Stevens-Johnson syndrome; TEN, toxic epidermal necrolysis

Conjunctivitis associated with systemic diseases, infectious diseases

\section{Drug history}

Toxic conjunctivitis, allergic conjunctivitis

Acute systemic reactions (SJS/TEN) main etiologies of "red eye" and their clinical characteristics.

\section{How to distinguish infectious conjunctivitis from non-infectious conjunctivitis}

Obtaining history from patients who present with conjunctivitis is crucial in order to arrive at the correct diagnosis. A focused ocular history should include the following: onset and duration of symptoms; laterality; impairment of vision; presence of itching; contact lens wear history; presence of fellow travelers such as recent upper respiratory infection, sinusitis, and lymphadenopathy; previous episodes of conjunctivitis; systemic allergies and medication; and history of exposure to chemical agents.

The presence of constitutional signs such as fever, malaise, fatigue, and contact with individuals with conjunctivitis helps to further narrow down the differential diagnosis. Physical examination, including checking for palpable lymph nodes, especially in the periauricular and submandibular areas, is of great importance. Ophthalmic examination should be performed to determine the type of discharge. Closer examination using a slit-lamp biomicroscope to evaluate the ocular surface structures including the palpebral conjunctiva for the presence of pseudomembranes, symblepharon, papilla or follicles, and the corneal tissue for the presence of opacities and infiltrates is absolutely essential.

Some of the clinical signs and symptoms that are used to help diagnose infectious conjunctivitis include the following: eye discharge, conjunctival injection, presence of red eye(s), eyelashes being stuck together in the morning, grittiness of the eye(s), eyelid or conjunctival edema, and history of contact with individuals with conjunctivitis. ${ }^{[7]}$

Allergic conjunctivitis may be underdiagnosed and undertreated. ${ }^{[8]}$ It is presented with itching, chemosis, and redness in the absence of any significant corneal involvement. ${ }^{[9]}$ The degree of conjunctival swelling is often out of proportion to conjunctival hyperemia. The main findings in vernal keratoconjunctivitis (VKC) are the presence of giant papillae in the superior tarsal conjunctiva accompanied by severe itching, ${ }^{[10]}$ while the presence of conjunctival scar and anterior subcapsular cataract supports the diagnosis of atopic keratoconjunctivitis (AKC). ${ }^{[11]}$

Another similar condition, chronic toxic conjunctivitis, may present with watery discharge, an initial papillary conjunctival reaction followed by a follicular reaction, punctate epithelial erosion of the cornea, and eyelid dermatitis. ${ }^{[12-14]}$ 
Table 2. Selected non-conjunctivitis etiologies of red eye

\section{Differential diagnosis}

Dry eyes

Blepharitis

Pterygium

Hordeolum, chalazion

Anterior segment tumors

Corneal abrasion, keratitis, corneal foreign body

Contact lens overwear

Subconjunctival hemorrhage

Scleritis

Iritis

Angle closure glaucoma

Carotid cavernous fistula

Endophthalmitis

Cellulitis
Symptoms

Burning and FB sensation. Symptoms are usually transient, worse with reading or watching TV due to decreased blinking. Symptoms are worse in dry, cold, and windy environments due to increased evaporation

Similar to dry eyes

Recurrent ocular redness

Eyelid pain and swelling

Variable

B sensation, relevant history including contact lens usage and occupational exposure

Relevant history
Ocular redness

Decreased vision, moderate to severe pain

Photophobia, pain, blurred vision. Symptoms are usually bilateral

Headaches, nausea, vomiting, ocular pain, decreased vision, light sensitivity, and seeing haloes around lights. Symptoms are usually unilateral.

Chronic red eye, may have a history of head trauma

Severe pain, photophobia, may have a history of eye surgery or ocular trauma

Pain, double vision, and fullness
Exam findings

Bilateral redness, superficial punctate keratopathy, meibomian glands dysfunction, decreased tear break-up time, small tear meniscus

Redness greater at the margins of eyelids, inflammation, telangiectasia, and crust around eyelashes

Visible conjunctival extension over the cornea

Palpable eyelid mass, may be tender or not

Variable

Corneal epithelial defects, corneal infiltration, corneal FB

Corneal epithelial defect

Blood under conjunctiva

Redness, bluish scleral hue

Decreased vision, poorly reacting pupils, constant eye pain radiating to temple and brow. Redness, severe photophobia, presence of inflammatory cells in the anterior chamber

Firm eye upon palpation, ocular redness with limbal injection. Appearance of a hazy/steamy cornea, moderately dilated pupils that are unreactive to light.

Dilated tortuous vessels (corkscrew vessels), bruits upon auscultation with a stethoscope

Redness, puss in the anterior chamber and photophobia

Redness and swelling of lids, may have restriction of the eye movements, may have a history of preceding sinusitis (usually ethmoiditis)

FB, foreign body; TV, television

\section{How to distinguish bacterial conjunctivitis from viral conjunctivitis}

Predicting the underlying etiology of conjunctivitis based on the presenting signs and symptoms may often result in an inaccurate diagnosis. In one study, centers with expertise in ocular surface disease had an accuracy rate of only $48 \%$ in making the correct diagnosis of adenoviral conjunctivitis. ${ }^{[15]}$ Several other studies demonstrated that bacterial pathogens are only isolated in $50 \%$ of cases of suspected bacterial conjunctivitis. ${ }^{[16]}$ In addition, 
one study reported that up to $52 \%$ of presumed cases of viral conjunctivitis were culture-positive for bacteria. $^{[15]}$

Traditionally, the following associations between the clinical history and the etiology of conjunctivitis were believed to be true; these principles were presented in many textbooks and were used to select patients in many clinical trials. ${ }^{[17]}$ For example, according to the major text books in ophthalmology (e.g., Krachmer, Duane, and Kanski), involvement of one eye followed by the involvement of the second eye within 24-48 hours is indicative of bacterial infection, while if the second eye becomes infected after 48 hours with an accompanying enlarged periauricular lymph node, a viral etiology should be considered. According to the same textbooks, a papillary conjunctival reaction or pseudomembranous conjunctivitis strongly suggests a bacterial origin for conjunctivitis while follicular conjunctival reaction is more likely to indicate a viral etiology.

There are many other associations between the etiology of conjunctivitis and symptoms that are thought to be true, but lack strong clinical evidence. For example, association between lack of itching and bacterial conjunctivitis have come under scrutiny in the recent years. Other associations that once thought to be true but lack evidence include: recent upper respiratory tract infection and lymphadenopathy in favor of viral conjunctivitis; sinusitis, fever, malaise, and fatigue in association with bacterial conjunctivitis; and previous history of conjunctivitis with bilateral involvement of the eyes in favor of viral and allergic but not bacterial conjunctivitis.

A meta-analysis in 2003 failed to find any clinical studies correlating the signs and symptoms of conjunctivitis with its underlying etiology. ${ }^{[17]}$ Following the above meta-analysis, a prospective study was conducted and found that combination of three signs, bilateral mattering of the eyelids, lack of itching, and no previous history of conjunctivitis were strong predictors of bacterial conjunctivitis. ${ }^{[18]}$ Having both eyes matter and their eyelashes adhere together in the morning was a stronger predictor for positive bacterial culture, and either itching or a previous episode of conjunctivitis made a positive bacterial culture less likely. In addition, types of the discharge (purulent, mucus, or watery) or other symptoms were not specific to any particular class of conjunctivitis.
A more recent meta-analysis, which analyzed the clinical data of 622 patients from three clinical trials, ${ }^{[19]}$ found that patients with purulent discharge or mild to moderate red eye were less likely to benefit from topical antibiotics; this finding reiterates lack of meaningful correlation between signs and symptoms and the underlying etiology in most cases of conjunctivitis. Another recent study in 2013 found a strong likelihood of positive bacterial culture results in patients with the "gluing of the eyelids" upon waking up in the morning, and the age above 50 at presentation. ${ }^{[20]}$

\section{How do laboratory findings help us?}

Clinicians may collect discharge samples from eyes with conjunctivitis and send them for microbiological evaluation. Conjunctival cultures are generally reserved for cases of suspected infectious neonatal conjunctivitis, recurrent conjunctivitis, conjunctivitis recalcitrant to therapy, conjunctivitis presenting with severe purulent discharge, and cases suspicious for gonococcal or chlamydial infection. ${ }^{[21]}$ Swabs from the discharge are better to be taken before the initiation of antimicrobial therapy. The swabs are then plated in various growth mediums in the laboratory for obtaining cultures. Sabouraud agar plates are used to identify fungus, and it should be utilized in patients with chronic blepharitis and those who are immunocompromised. Anaerobic culture plates may also be helpful, especially in patients with a history of previous surgery or trauma. ${ }^{[22]}$ If antimicrobial therapy has already been started, they should be stopped 48 hours prior to obtaining cultures. In a five-year review of 138 pediatric ocular surface infections, the most common organisms were coagulase-negative staphylococci, followed by Pseudomonas aeruginosa and Staphylococcus aureus. ${ }^{[23]}$

Nucleic acid amplification techniques, requiring special swabs, may be used in diagnosing viral infections, where a multitude of polymerase chain reaction (PCR) tests for detection of viruses are available.

Although primary studies from in-office rapid antigen testing for adenoviruses report 89\% sensitivity and up to $94 \%$ specificity, ${ }^{[21]}$ the results of more recent studies point toward a high specificity but only moderate sensitivity ranging from 39.5\% to $50 \% .^{[24]}$ Accordingly, it may be suggested 
that negative Adeno-Plus test results should be confirmed by real-time PCR owing to its suboptimal sensitivity.

For those suspected of having allergic conjunctivitis, skin scratch test or intradermal injection of common allergens, and assays for detecting elevated in vitro levels of specific serum IgE may be used; however, the diagnosis of allergic conjunctivitis remains a clinical one.

\section{Viral conjunctivitis}

Viral conjunctivitis is the most common overall cause of infectious conjunctivitis, and it is usually secondary to inoculation of the ocular surface with the adenoviruses. ${ }^{[25,26]}$ Less frequently, other viruses may be the underlying etiology in viral conjunctivitis; amongst them, herpes simplex virus (HSV), varicella zoster virus (VZV), and enterovirus have been the subject of investigation. ${ }^{[27]}$

\section{Adenoviral conjunctivitis}

As the leading cause of infectious conjunctivitis worldwide, up to $90 \%$ of viral conjunctivitis cases are caused by adenoviruses. ${ }^{[28]}$ Recent advances in genome sequencing of human adenoviruses (HAdV) have identified over 72 unique HAdV genotypes classified into seven different species (HAdV-A through HAdV-G), with HAdV-D species having the most members and the strongest association with viral conjunctivitis. ${ }^{[29,30]}$

Perhaps the most common form of infection by the adenoviruses in children is pharyngoconjunctival fever (PCF) caused by HAdV types 3,4 , and $7 .^{[31-33]}$ This condition is usually characterized by the presence of fever, pharyngitis, periauricular lymphadenopathy, and acute follicular conjunctivitis. Additional ocular surface findings include edema, hyperemia, and petechial hemorrhages of the conjunctiva as a result of interaction between pro-inflammatory cytokines and conjunctival vasculature. ${ }^{[32]}$ This condition is self-limited, often resolving spontaneously in two-three weeks without any treatment.

The most severe ocular manifestation of adenoviral infection is the epidemic keratoconjunctivitis (EKC); this condition affects both the conjunctiva and cornea, leaving behind long-lasting and permanent ocular surface changes and visual disturbances. Ocular manifestations of EKC include conjunctival discharge, follicular conjunctivitis, corneal subepithelial infiltrates (SEI), corneal scarring, development of conjunctival membranes and pseudomembranes, and symblepharon formation (Figures 1 and 2).

Classically, serotypes $8,19,37$, and less frequently serotype 4 were believed to be associated with EKC, but more recently, HAdV-D53 and HAdV-D54 have been identified in several outbreaks and are thought to be responsible for the majority of EKC cases. ${ }^{\text {[30] }}$

Pseudomembranes, which are sheets of fibrinrich exudates without blood or lymphatic vessels, may be encountered in the tarsal conjunctiva of the EKC patients. ${ }^{[35]}$ Depending on the intensity of inflammation, true conjunctival membranes may also form in EKC. True membranes, once form, can lead to the development of subepithelial fibrosis and symblepharon; additionally, they tend to bleed severely upon removal. ${ }^{[36]}$

Cornea is another tissue that may become adversely affected in EKC. Replication of the virus in the corneal epithelium may cause superficial punctate keratopathy, followed by focal areas of epithelial opacities. ${ }^{[3]}$ Focal SEI in the anterior stroma of the cornea appears approximately 710 days following the initial involvement of the eyes with EKC $^{[38]}$ (Figure 3). These opacities may persist for years, and they may be associated with visual disturbance, photophobia, and astigmatism. The incidence of SEl formation in EKC has been reported to vary from 49.1 to 80\%. ${ }^{[39]}$ An immunologic reaction to the replicating adenoviruses in anterior stromal keratocytes is hypothesized to be the underlying mechanism for the formation of SEls. The observation that these opacities recur following discontinuation of steroids supports the hypothesis. ${ }^{[40]}$

Adenovirus conjunctivitis is very contagious and it may be transmitted up to $50 \%$ of the time according to some reports. ${ }^{[41,42]}$ The virus may spread through contaminated fingers, medical devices, contaminated water at the swimming pools, or by sharing of personal items; as many as $46 \%$ of individuals with viral conjunctivitis had positive viral culture grown from their hands according to one study. ${ }^{[4]}$ The adenovirus is a very hardy organism, and it is reported to be resistant to $70 \%$ isopropyl alcohol and 3\% 


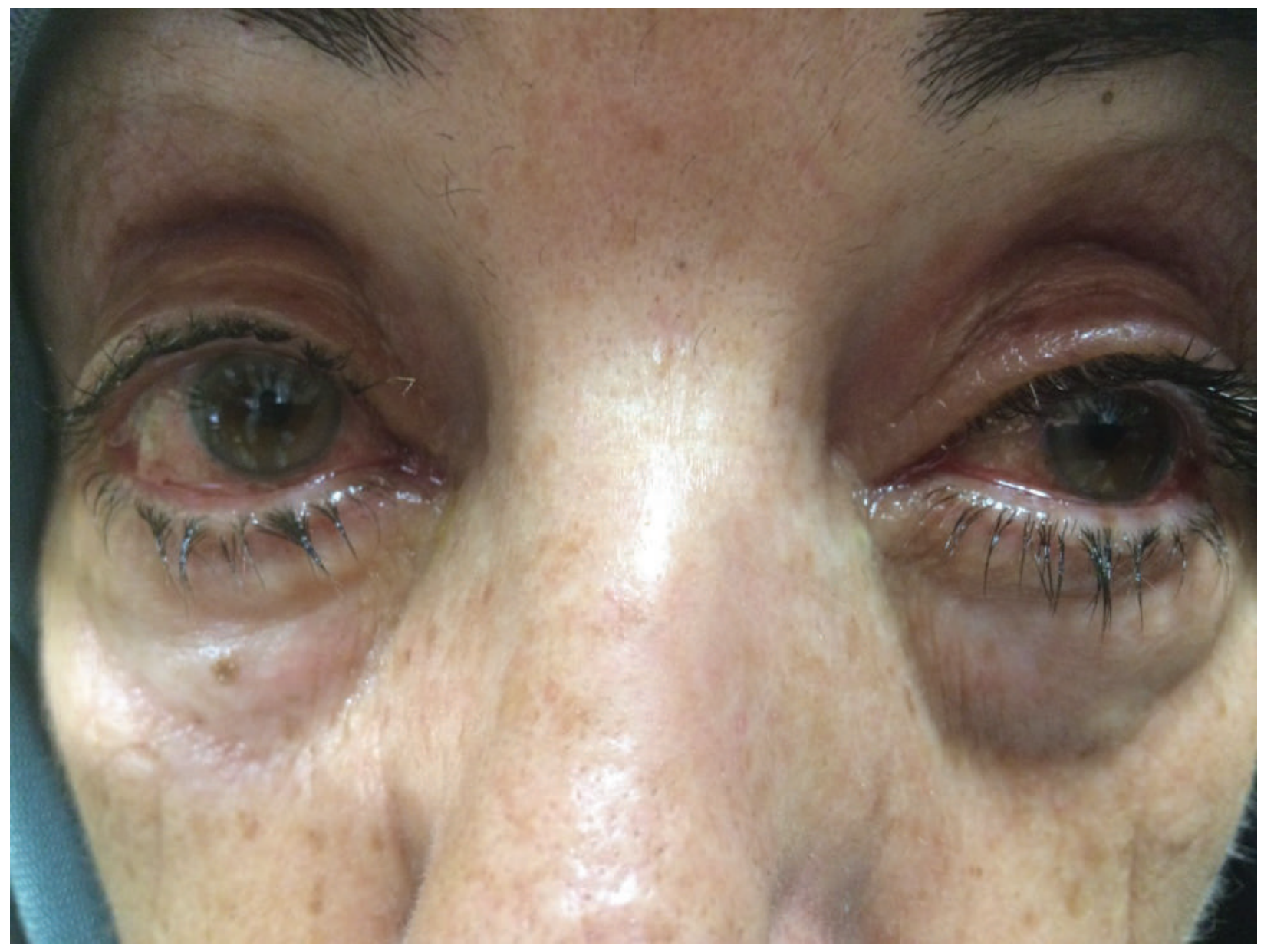

Figure 1. Adenoviral conjunctivitis presenting as bilateral watery eyes.

hydrogen peroxide. ${ }^{[4]]}$ The American Academy of Ophthalmology recommends using a 1:10 dilute bleach solution (sodium hypochlorite) to disinfect the office equipment and instruments against common infectious agents encountered in eye care clinics including the adenoviruses. ${ }^{[45]}$

Due to the highly contagious nature of viral conjunctivitis, frequent hand washing, meticulous disinfection of medical instruments, and isolation of conjunctivitis patients from the rest in the healthcare provider's office has been recommended. ${ }^{[46]}$ The incubation period for the adenovirus is approximately 5-12 days, while the infected individuals can transmit the disease for up to 14 days from the time they are infected. ${ }^{[41]}$

There is no single effective treatment modality for viral conjunctivitis; however, use of frequent artificial tears, antihistamines containing eye drops, or cold-compresses seem to alleviate many of the clinical symptoms that are associated with this condition. ${ }^{[4,48]}$ Topical and oral antiviral medications do not appear to be useful. ${ }^{[4,48]}$ In addition, antibiotic eye drops do not play a role in treating viral conjunctivitis and may even obscure the clinical picture by inducing ocular surface toxicity. ${ }^{[15,16]}$ Other concerns with using antibiotic drops include increased bacterial resistance and the possibility of spreading the disease to the contralateral eye by cross-contamination through the infected bottles. $^{[42]}$

Membranes or pseudomembranes may be peeled at the slit-lamp by using a pair of jeweler forceps or cotton swab after anesthetizing the ocular surface. This is done to alleviate patient discomfort and prevent future scar formation.

Monotherapy against viral conjunctivitis with Povidone-iodine $2 \%$ have been investigated in a pilot study. The authors discovered that topical administration of Povidone-iodine $2 \%$ four times a day for one week led to complete resolution of the disease in three-quarters of the eyes. ${ }^{[49]}$ 


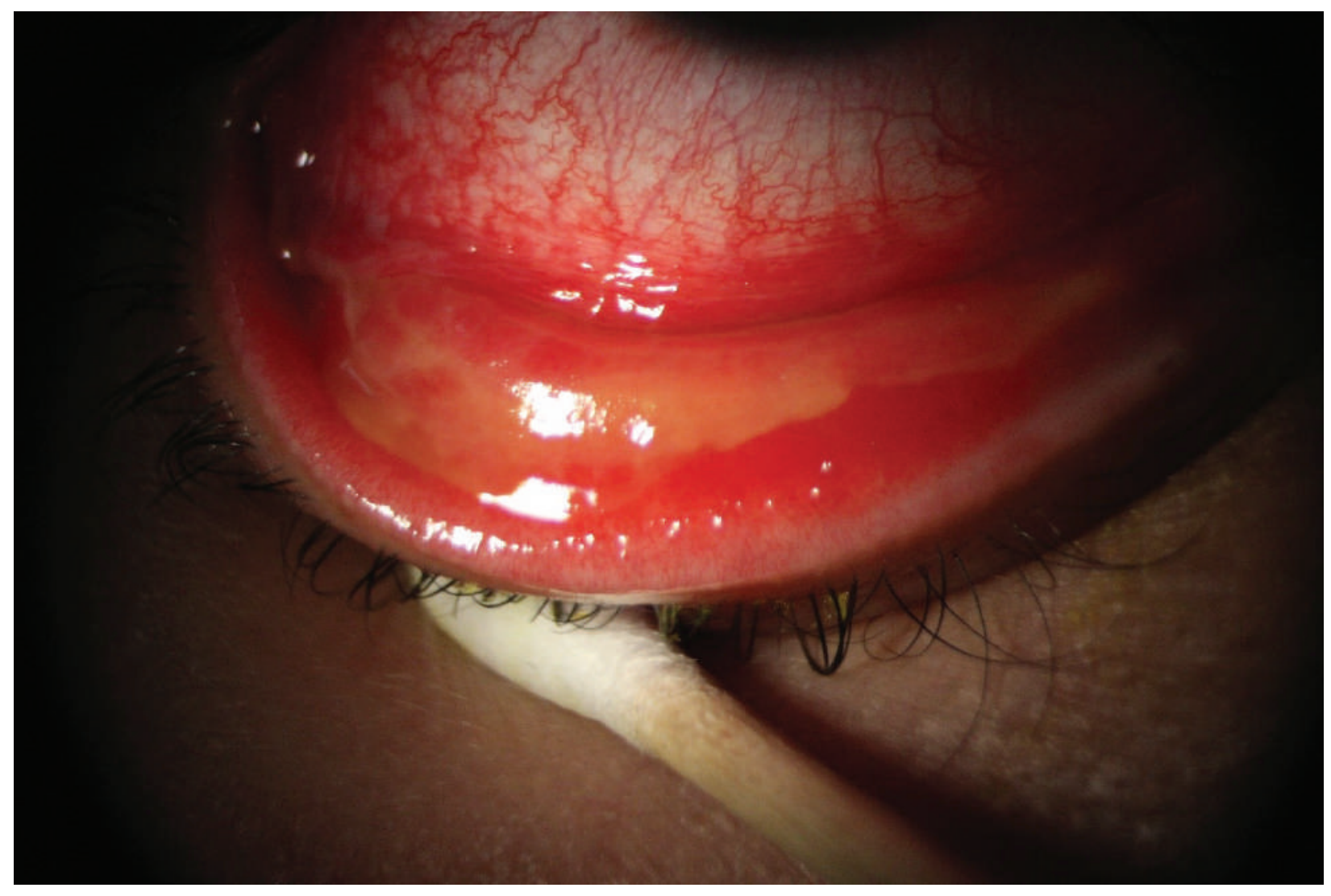

Figure 2. Pseudomembrane formation in a patient with adenoviral conjunctivitis.

The American Academy of Ophthalmology suggests that topical corticosteroids play an important role in the treatment of conjunctivitis, but they should be used judiciously and with caution in selected cases. ${ }^{[4]}$ Indications for steroid usage in viral conjunctivitis are membrane formation and sub-epithelial infiltration associated with severe photophobia and decreased vision. Prolonging the duration of adenoviral conjunctivitis, exacerbation of HSV keratitis, and an increase in intraocular pressure are the main adverse effects of indiscriminate use of topical corticosteroids.

Prolongation of viral shedding following monotherapy with corticosteroids has been reported; ${ }^{[50]}$ however, combination therapies with corticosteroids and anti-infective agents (i.e., antibiotics) have proven to be effective in treating viral and bacterial conjunctivitis. ${ }^{[51,52]}$

Ophthalmic formulations of PVPI/dexamethasone are widely investigated. PVP-I $0.4 \% /$ dexamethasone $0.1 \%$ suspension, PVP-I 1.0\%/dexamethasone $0.1 \%$, and PVP-I $0.6 \% /$ dexamethasone $0.1 \%$ have been used, and the results suggest that the combination therapies reduce patient symptoms and eradicate the virus effectively. ${ }^{[50,53-55]}$

Ongoing phase 3 , randomized, doublemasked, controlled studies will further clarify the efficacy and safety of combined PVPI/dexamethasone in adenoviral conjunctivitis (ClinicalTrials.gov identifiers: NCT0299855441 and NCT0299854142) and bacterial conjunctivitis (ClinicalTrials.gov identifiers: NCT03004924).

Use of 1 and $2 \%$ cyclosporine-A (CsA) eye drops have been advocated for the treatment of SEls, and it has been demonstrated to be effective in improving patient symptoms and reducing the amounts of infiltrates. ${ }^{[30,56]}$ However, Jeng et al suggested that it might be difficult to wean patients completely off CsA once they have started it; in their study, when CsA was stopped, SEls returned, necessitating reinstitution of the CsA eye drops. ${ }^{[57]}$ This finding is in contrast with the Reinhard's pilot study, where no recurrence was observed after discontinuation of the CsA drops. ${ }^{[58]}$ In a small study consisting of 39 patients, administration of $1 \%$ cyclosporine-A (four times a day) during the acute phase of viral conjunctivitis and continuing 


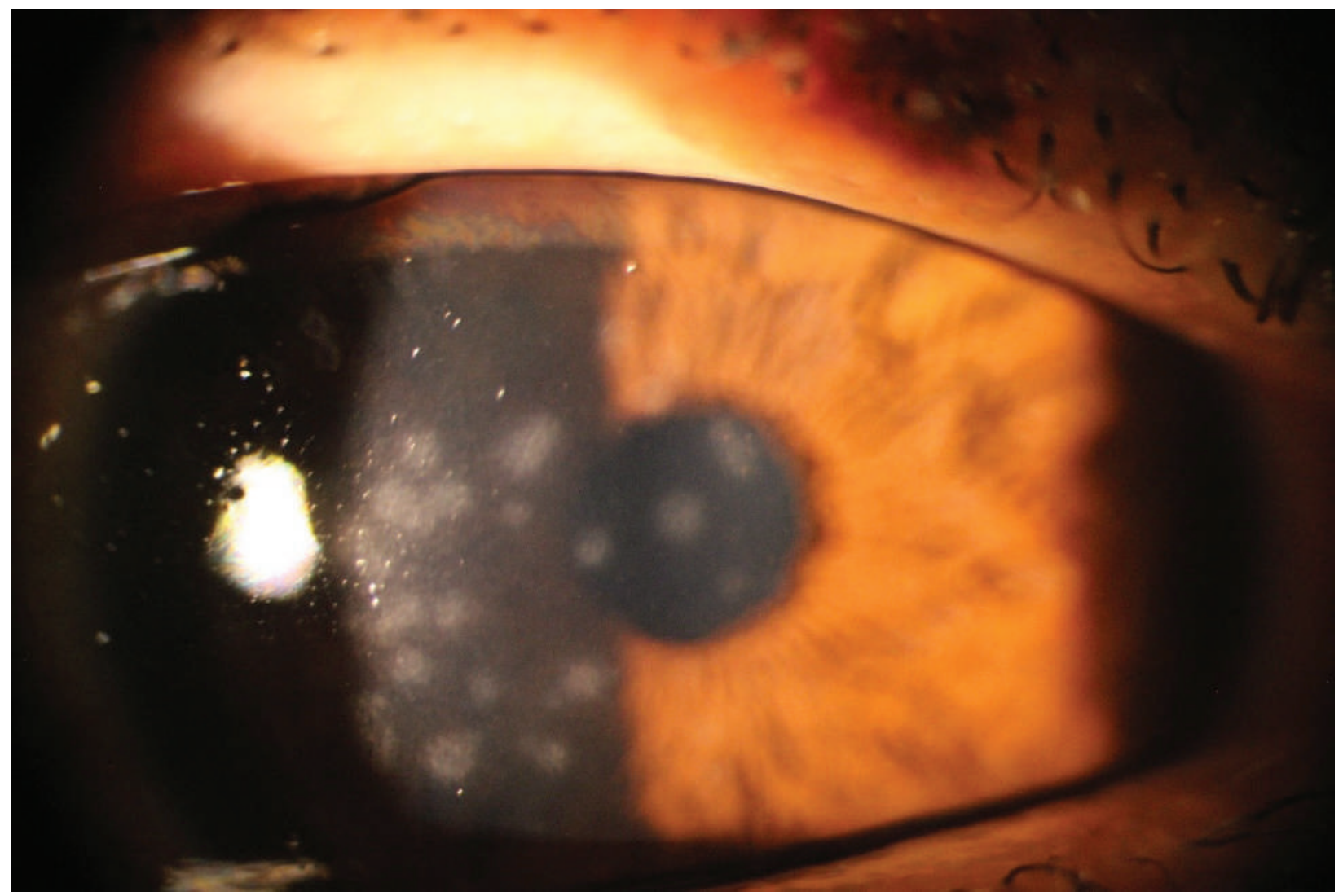

Figure 3. Subepithelial infiltrations in a patient with adenoviral conjunctivitis.

it thereafter for 21 days lowered the incidence of corneal opacities significantly. ${ }^{[59]}$ A case-controlled double-blinded randomized clinical trial is needed to investigate the effectiveness of cyclosporine-A and to formulate an ideal tapering regiment for this medication.

The use of topical tacrolimus eye drops has also been investigated for the treatment of SEls secondary to adenoviral keratoconjunctivitis. When tacrolimus eye drops or ointments were used for an average of six months, a significant reduction in the size and numbers of SEls was observed in $60 \%$ of the cases, while in $31.76 \%$ of the eyes, SEls were eliminated after one year. ${ }^{[60]}$ There was also a statistically significant improvement in the visual acuity of the patients with the use of topical tacrolimus.

\section{Herpetic conjunctivitis}

It is estimated that $1.3-4.8 \%$ of all cases of acute conjunctivitis are caused by HSV infection. [61-63] HSV often causes a unilateral follicular conjunctivitis, which may be accompanied by a thin watery discharge and associated vesicular lesions on the skin of the eyelids. Treatment consists of topical antiviral agents, including ganciclovir, idoxuridine, vidarabine, and trifluridine. The purpose of the treatment is to reduce virus shedding and the chance of the development of keratitis.

Ocular involvement with herpes zoster virus, especially when the first and second branches of the trigeminal nerve are involved, can lead to conjunctivitis in $41.1 \%$ of cases, eyelid lesions in $45.8 \%$, uveitis in $38.2 \%$, and corneal lesions such as SEls, pseudodendrites, and nummular keratitis in another $19.1 \% .^{[64,65]}$

\section{Acute hemorrhagic conjunctivitis}

Acute hemorrhagic conjunctivitis (AHC) is an extremely contagious form of viral conjunctivitis. It manifests by foreign body sensation, profuse tearing, eyelid edema, dilatation of conjunctival vessels, chemosis, and subconjunctival hemorrhage. In a small proportion of patients, fever, fatigue, and leg pain may ensue. Two 
picornaviruses, namely enterovirus 70 (EV70) and coxsackievirus A24 variant (CA24v), as well as certain subtypes of adenoviruses are believed to be the responsible pathogens. ${ }^{[66-68]}$ Like the other forms of conjunctivitis, $\mathrm{AHC}$ is also believed to be transmitted primarily by hand-toeye-to-hand contact and infected fomites. ${ }^{[69]}$ The condition is self-limited and the symptoms diminish gradually during the first week of infection and completely resolves after $10-14$ days. ${ }^{[69]}$ Medical intervention aims primarily at controlling the large outbreaks as well as instituting preventative measures to protect the vulnerable groups, such as children, elderly, pregnant women, and immunocompromised individuals, by encouraging frequent handwashing and reducing contact with the affected individuals. ${ }^{[68]}$

\section{Miscellaneous viral conjunctivitis}

Infection with Molluscum contagiosum (MC) is characterized by multiple umblicated and papular skin lesions caused by Pox- 2 virus. Skin-to-skin contact and sexual intercourse are the main routes of transmission. Shedding of the viral proteins from the eyelid lesions into the tear film leads to chronic follicular conjunctival reaction, punctate keratopathy, and subepithelial pannus. Rarely, primary MC lesions are found in the conjunctiva. ${ }^{[70]}$

Ebola hemorrhagic fever is a fatal disease caused by the species of ebolavirus. Conjunctival injection, subconjunctival hemorrhage, and tearing have been reported in the affected individuals. ${ }^{[71]}$ Conjunctival injection, which is often bilateral and present in up to $58 \%$ of cases, has been identified in both the acute and late stages of this disease and may play an important role in the early diagnosis of this potentially deadly condition. ${ }^{[72]}$ While humanto-human transmission through bodily fluids can spread the infection, the natural reservoir is thought to be the fruit bat. ${ }^{[3]}$

Coronaviruses include a broad family of viruses that normally affect animals, although some strains can spread from animals to humans. ${ }^{[74]}$ The most recently isolated strain of coronavirus, "2019nCoV", has made the headlines since it was first recognized in December 2019 in China. COVID-19 has been reported to cause fever, cough, shortness of breath, and even death. ${ }^{[75,76]}$ Some reports have suggested that this virus can cause conjunctivitis and be transmitted via the conjunctival secretions of the infected individuals. ${ }^{[76]}$ All healthcare professionals including the ophthalmologists should be vigilant in approaching patients with conjunctivitis and respiratory symptoms, especially if they report a recent history of travel to high risk regions. ${ }^{[76]}$

\section{Bacterial conjunctivitis}

While in adults, bacterial conjunctivitis is less common than viral conjunctivitis, in children, it is encountered more frequently. ${ }^{[7]}$ Bacterial conjunctivitis can result from either a direct contact with infected individuals or from abnormal proliferation of the native conjunctival flora. ${ }^{[78]}$ Contaminated fingers, ${ }^{[41]}$ oculogenital spread, ${ }^{[47]}$ and contaminated fomites ${ }^{[79]}$ are common routes of transmission. In addition, certain conditions such as compromised tear production, disruption of the natural epithelial barrier, abnormality of adnexal structures, trauma, and immunosuppressed status increase the likelihood of contracting bacterial conjunctivitis. ${ }^{[4]}$

Acute bacterial conjunctivitis is most often caused by Staphylococcus species, Haemophilus influenza, Streptococcus species, Moraxella catarrhalis, and gram-negative intestinal bacteria. ${ }^{[0]}$ In younger children, minor epidemics may occur secondary to $H$. influenza or $S$. pneumonia. Acute bacterial conjunctivitis manifests by foreign body sensation and increased ocular secretion in addition to moderate conjunctival hyperemia (Figure 4).

Several studies on bacterial conjunctivitis ${ }^{[81,82]}$ demonstrate that sticky eyelids and itching may be present in approximately $90 \%$ of the affected individuals; these findings are followed by the less frequently encountered signs and symptoms such as purulent secretion and ocular burning. $H$. influenza conjunctivitis may be associated with acute otitis media and upper respiratory tract infection. ${ }^{[80]}$

In more than $60 \%$ of cases, spontaneous cure occurs within one-two weeks, ${ }^{[83]}$ and serious complications are extremely rare. ${ }^{[84]}$ However, presence of a large population of bacteria on the conjunctiva exposes the patient to a higher risk of keratitis, particularly in conditions associated with corneal epithelial defects, such as dry eye. ${ }^{[80]}$

Although topical antibiotics reduce the duration of the disease, no difference in the outcome is seen 
between the treatment and placebo groups. In a meta-analysis, ${ }^{[81]}$, consisting of 3,673 patients from 11 randomized clinical trials, antibiotic treatment increased the rate of clinical improvement by $10 \%$ compared to placebo. Both " 2 to 5 " and " 6 to 10 " day regiments were included in this analysis. Although, highly virulent bacteria can potentially inflict serious damage to the ocular surface and the eye ${ }^{[78]}$, no sight-threatening complications were reported in any of the placebo groups in the aforementioned meta-analysis. ${ }^{[85]}$

All broad-spectrum antibiotic eye drops seem to be effective in treating bacterial conjunctivitis and it is unlikely that there is a significant difference among various antibiotics in achieving clinical cure. Factors that influence antibiotic choice are local availability, patient allergies, resistance patterns, and cost.

From a large systematic review, it was concluded that topical antibiotics were more effective in achieving clinical and microbial cure when patients had positive bacterial cultures. ${ }^{[21]}$ However, no significant difference has been reported in clinical cure rate when different frequencies of the antibiotics were administered. ${ }^{[86,87]}$ Due to lengthening the course of the illness and potentiating the infection, topical steroids should be avoided ${ }^{[47]}$ (Table 3).

\section{Methicillin-resistant S. aureus conjunctivitis}

The term methicillin-resistant $S$. aureus (MRSA) refers to Staphylococcus aureus species that are resistant to methicillin antibiotic; however, nowadays the term is used to describe resistance to all $\beta$-lactam antimicrobials. ${ }^{[8]}$ Growing in prevalence, 3-64\% of all ocular Staphylococcus conjunctival infections are MRSA conjunctivitis. ${ }^{[89]}$ Suspected cases need to be treated with fortified vancomycin eye drops or ointments. ${ }^{[90]}$ Culturedirected administration of antimicrobials, effective dosing, considering the local resistance patterns, and appropriate antiseptic strategies should be applied to restrict the spread of MRSA conjunctivitis. $^{\text {[91] }}$

\section{Chlamydial conjunctivitis}

Chlamydia trachomatis may cause a variety of ocular surface infections including trachoma, neonatal conjunctivitis, and inclusion conjunctivitis.
Serotype D-K are causative agents for neonatal conjunctivitis and adult inclusion conjunctivitis, while trachoma is caused by serotypes $A, B, B a$, and $C$. $^{\text {[92] }}$

Inclusion conjunctivitis is reported to cause 1.8$5.6 \%$ of all cases of acute conjunctivitis, $[61,62,93]$ where the majority of cases are unilateral and have concurrent genital infection. ${ }^{[94]}$ Patients often present with mild mucopurulent discharge and follicular conjunctivitis persisting for weeks to months. ${ }^{[77]}$ Up to $54 \%$ of men and $74 \%$ of women are reported to have simultaneous genital infection. ${ }^{[95]}$ The disease is frequently acquired via oculogenital spread. ${ }^{[47]}$ Treatment with systemic antibiotics such as oral azithromycin and doxycycline is efficacious, while addition of topical antibiotics is not beneficial. Treatment of sexual partners and looking for the evidence of coinfection with gonorrhea must be instituted.

As the leading cause of infectious blindness in the world, trachoma affects 40 million individuals worldwide; this infection is prevalent in areas with poor hygiene. Although mucopurulent discharge is the initial presenting sign, in the later stages, scarring of the eyelids, conjunctiva, and cornea may lead to loss of vision. A single dose of oral azithromycin $(20 \mathrm{mg} / \mathrm{kg})$ in addition to oral tetracycline or erythromycin for three weeks is very effective. Patients may also be treated with topical antibiotic ointments, such as tetracycline and erythromycin, for six weeks. ${ }^{[96,97]}$

In newborns, chlamydia can cause conjunctivitis following passage through an infected birth canal. The acute phase, which typically begins between days 5 and 14 following vaginal delivery, is characterized by purulent discharge, erythema and edema of the eyelids and conjunctiva. ${ }^{[98]}$ More prevalent than gonococcal conjunctivitis (GC), neonatal conjunctivitis secondary to $C$. trachomatis is considered the most frequent infectious cause of neonatal conjunctivitis worldwide. ${ }^{[98-100]}$

Although the chlamydial conjunctivitis has a mild course, scarring of the cornea and/or conjunctiva have been reported in untreated cases. ${ }^{[101]}$ It is important to note that up to $20 \%$ of the neonates who are exposed to chlamydia may develop pneumonia; in these, $50 \%$ demonstrate a previous history of conjunctivitis. ${ }^{[102]}$

A recent meta-analysis supports the superiority of traditional treatment with systemic erythromycin at $50 \mathrm{mg} / \mathrm{kg}$ per day (given in four divided doses 
Table 3. Ophthalmic drug therapies for acute bacterial conjunctivitis.

Antibiotic agents

\section{Treatment}

\section{Aminoglycosides}

Gentamicin

Tobramycin

Ointment: $4 \times / d$ for 1 wk Solution: $1-2$ drops $4 \times / d$ for $1 w k$

Fluoroquinolones

Besifloxacin

Ciprofloxacin

Gatifloxacin

Levofloxacin

Moxifloxacin

Ofloxacin

\section{Macrolides}

Azithromycin

Erythromycin

\section{Sulfonamides}

Sulfacetamide

\section{Combination drops}

Trimethoprim/polymyxin B
Ointment: $3 \times / d$ for $1 \mathrm{wk}$

\section{1 drop $3 \times / d$ for $1 w k$}

Ointment: $3 \times / d$ for 1 wk Solution: $1-2$ drops $4 \times / d$ for 1 wk $3 \times / d$ for 1 week

1-2 drops $4 \times / \mathrm{d}$ for $1 \mathrm{wk}$

$3 \times / d$ for $1 w k$

$1-2$ drops $4 \times / d$ for $1 \mathrm{wk}$

$2 \times / d$ for $2 \mathrm{~d}$; then 1 drop daily for $5 \mathrm{~d}$

$4 \times / d$ for $1 w k$

Ointment: $4 \times / \mathrm{d}$ and at bedtime for $1 \mathrm{wk}$ Solution: $1-2$ drops every $2-3 \mathrm{~h}$ for $1 \mathrm{wk}$

1 or 2 drops $4 \times / d$ for 1 wk

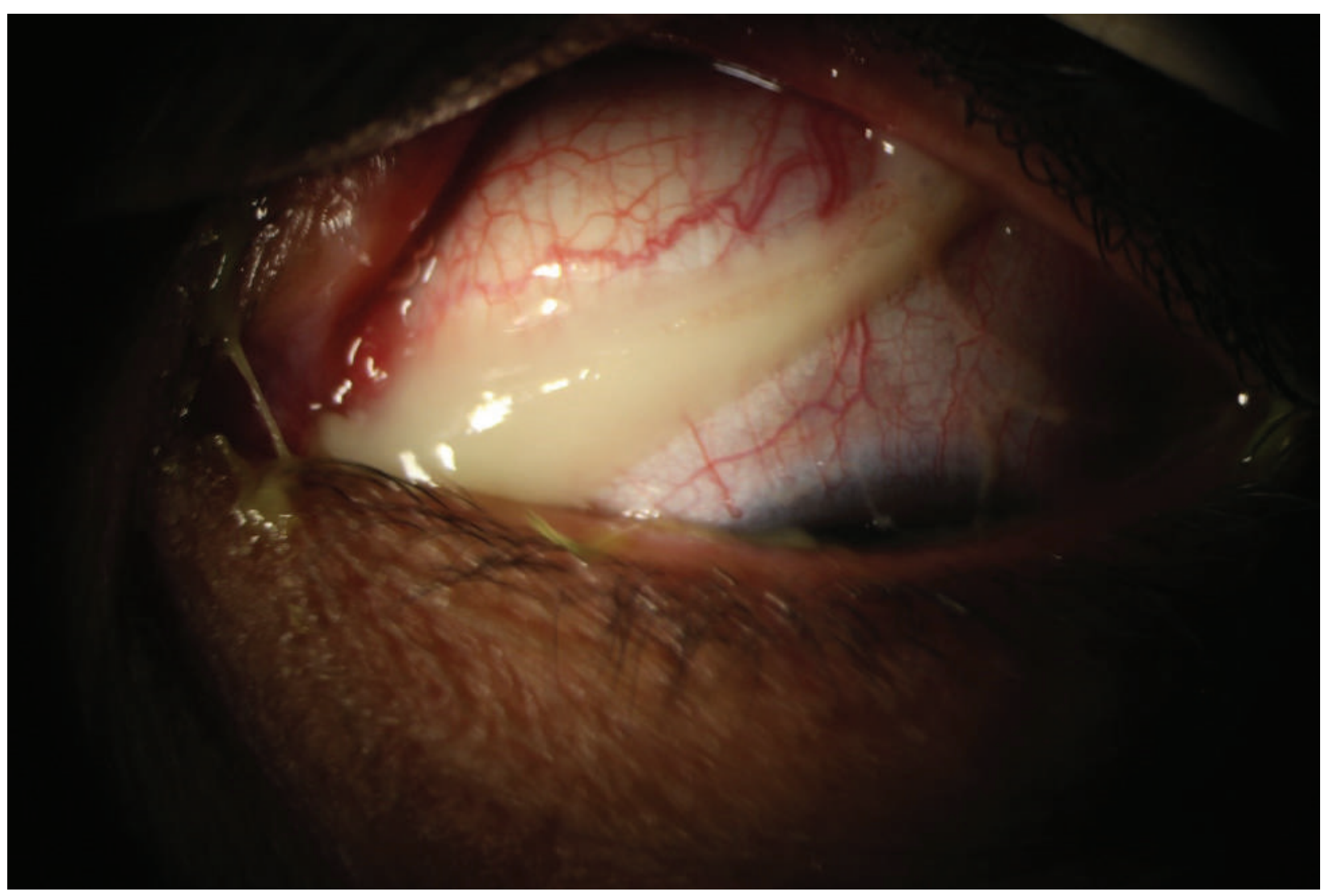

Figure 4. Thick purulent discharge in a patient with acute bacterial conjunctivitis. 


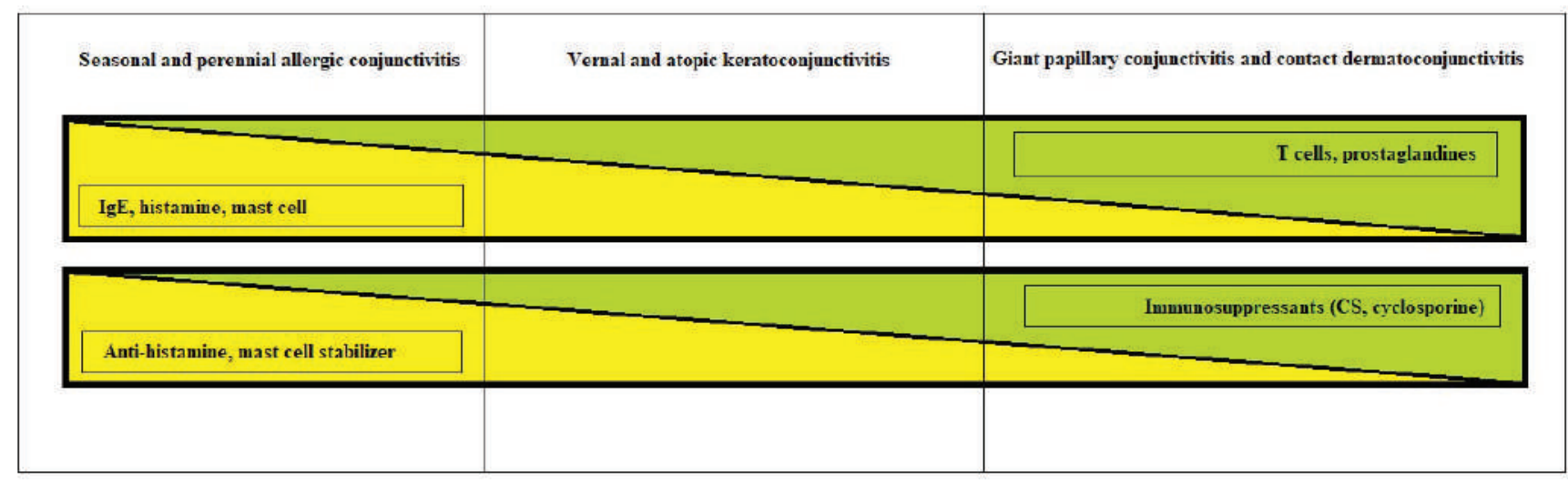

Figure 5. Spectrum of allergic conjunctivitis. CS, corticosteroid

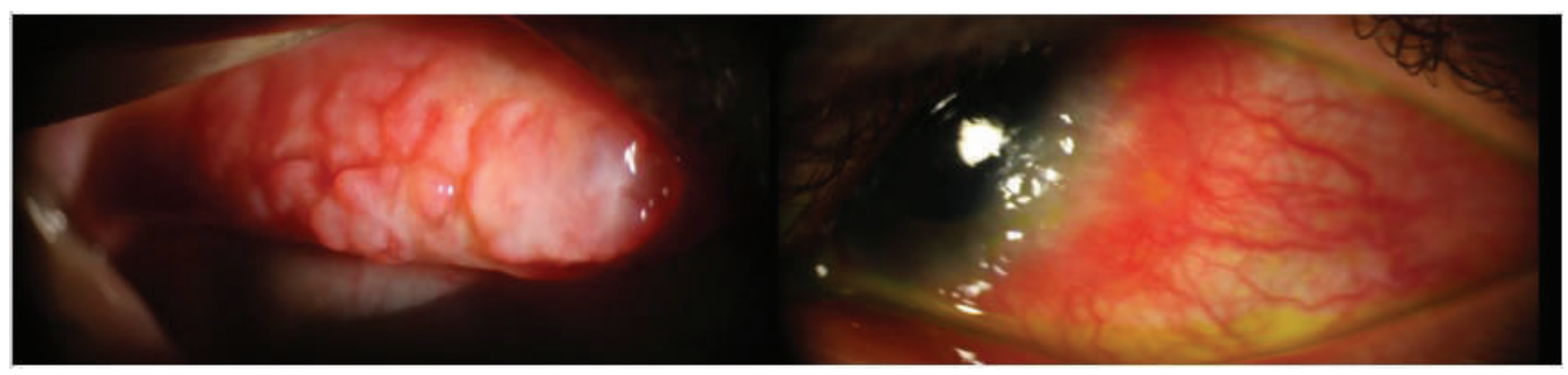

Figure 6. Cobblestone appearance of large conjunctival papillae in a patient with VKC (left). Limbal VKC with Horner-Trantas dots in another patient (right).

for two weeks), in comparison to topical antibiotic therapy alone. ${ }^{[103]}$ A recent study evaluating the efficacy of azithromycin in neonatal chlamydial conjunctivitis $^{[104]}$ demonstrated superiority of erythromycin over azithromycin; however, risk of pyloric stenosis related to the use of erythromycin may reduce its clinical use in neonates in the future. ${ }^{[103]}$ Additionally, lessfrequent dose of azithromycin may improve compliance. ${ }^{[105]}$

\section{Gonococcal conjunctivitis (GC)}

Typically viewed as a condition affecting the neonates, GC, however, affects other age groups as well. ${ }^{[106]}$ Neisseria gonorrhoeae is a common cause of hyperacute conjunctivitis in neonates and sexually active adults. ${ }^{[78]}$ Ocular infection with $N$. gonorrhea is associated with a high prevalence of corneal perforation. ${ }^{[80]} \mathrm{GC}$ should be considered as the causative agent in neonates who present with conjunctivitis in days 2 to 5 after delivery. ${ }^{[106]}$ In both neonatal and non-neonatal populations, eye exam may reveal conjunctival injection and chemosis along with copious mucopurulent discharge; a tender globe with periauricular lymphadenopathy may also be associated with this type of conjunctivitis. ${ }^{[06]}$

The suggested treatment for neonates include single dose of ceftriaxone (25 to $50 \mathrm{mg} / \mathrm{kg}$ ), or cefotaxime (100 mg/kg IV or IM), in addition to hourly saline irrigation of the ocular surface. ${ }^{[106-108]}$ Non-neonates can be treated with combination of $1 \mathrm{gm}$ of IM ceftriaxone given in a single dose and $1 \mathrm{gm}$ of oral azithromycin (which is used to treat the frequently encountered chlamydial coinfection). Irrigation of the ocular surface with saline solution is not necessary in adults. $^{[106]}$

\section{Allergic conjunctivitis}

Ocular allergy can affect the entire ocular surface including conjunctiva, eyelids, and cornea. According to the immunological mechanism responsible for the final clinical picture, Leonardi et al have classified ocular allergic conditions 


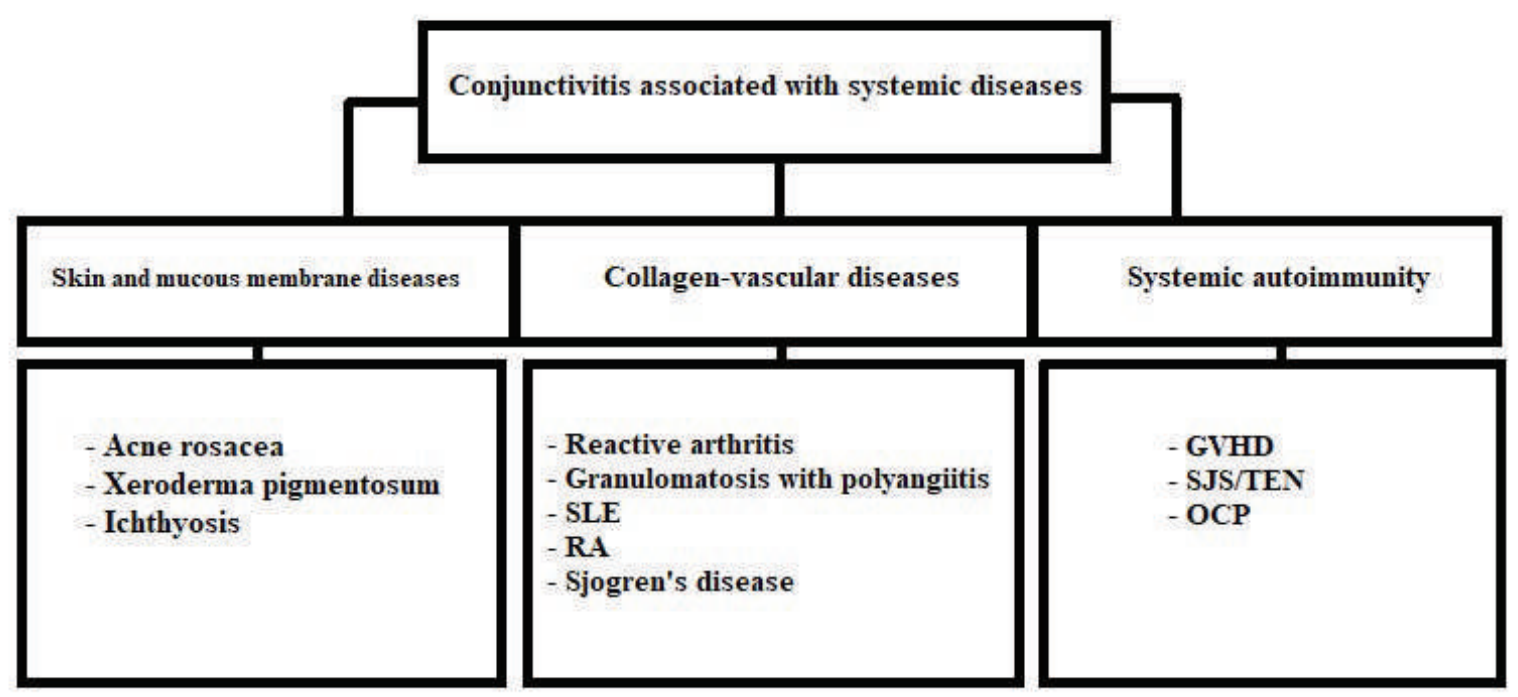

Figure 7. Some systemic and dermatological conditions associated with conjunctivitis.

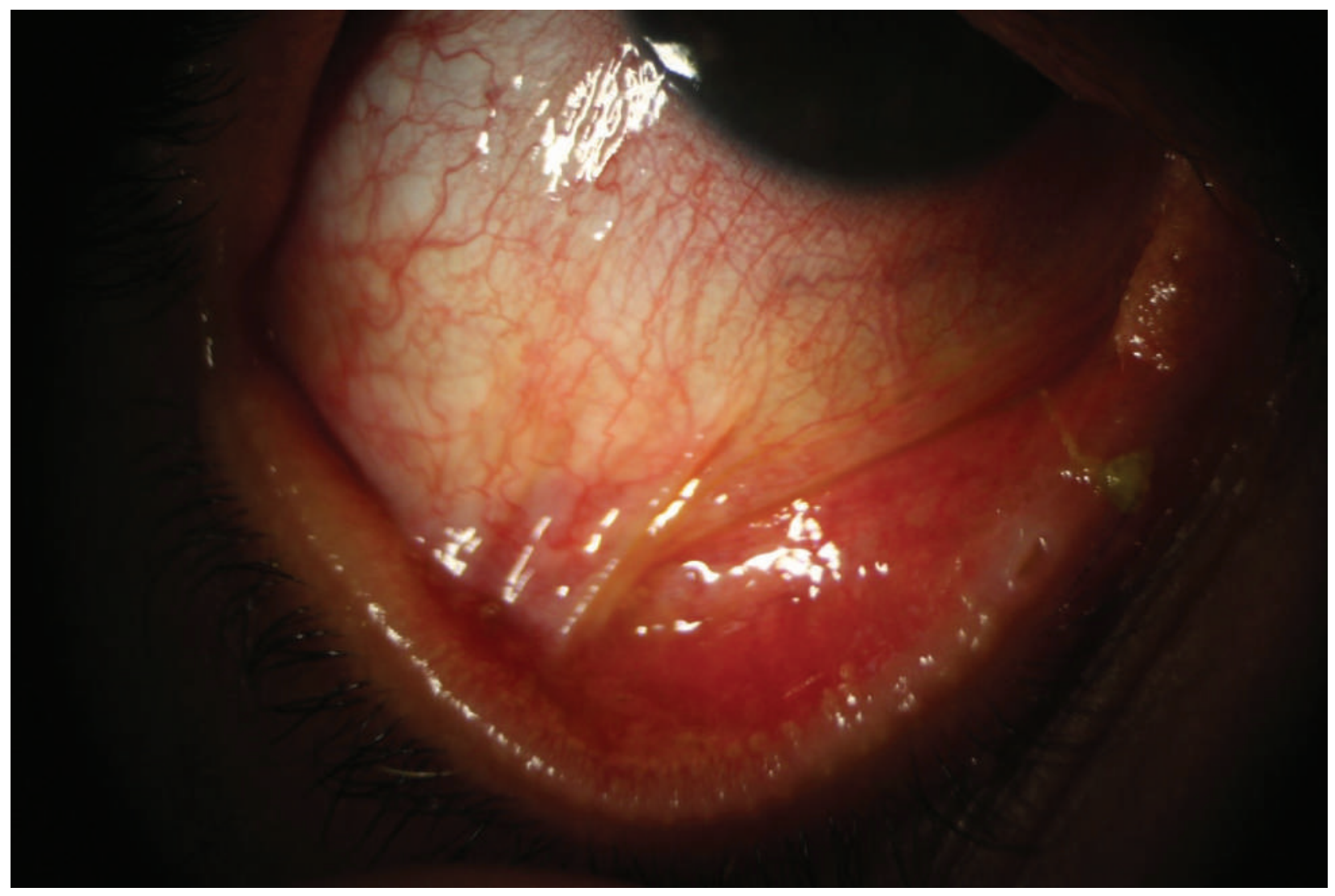

Figure 8. Symblepharon formation in a patient with ocular cicatricial pemphigoid.

into three main categories: ${ }^{[109]}$ IgE-mediated reactions, including seasonal allergic conjunctivitis (SAC) and perennial allergic conjunctivitis (PAC); combined IgE and non-IgE-mediated reactions, including VKC and AKC; and non-IgE-mediated reactions, including giant papillary conjunctivitis (GPC) and contact dermatoconjunctivitis (CDC) (Figure 5). 
Seasonal allergic conjunctivitis (SAC) and perennial allergic conjunctivitis (PAC)

SAC and PAC are considered as the most prevalent allergic ocular conditions, affecting $15-20 \%$ of the population. ${ }^{[10]}$ The pathogenesis is predominantly an IgE-mediated hypersensitivity reaction, and allergen-specific IgE antibodies are found in almost all cases of SAC and PAC. ${ }^{[111]}$ Activation of mast cells contributes to increased levels of histamine, prostaglandins, and leukotrienes in the tear film. This phase, which is known as the early response phase, clinically lasts $20-30 \mathrm{~min} \cdot{ }^{[8]}$

SAC, also known as hay fever conjunctivitis, is seen in all age groups. The ocular manifestations occur predominantly during the spring and summer months when pollens from the trees and plants are released into the air. PAC on the other hand can occur throughout the year with exposure to more common allergens such as animal hair, mites, and feathers. ${ }^{[112]}$ Clinical signs and symptoms are similar in SAC and PAC, and include itching and burning of the eyes, tearing, and rhinorrhea. Corneal involvement is rarely seen. ${ }^{[9]}$

\section{Vernal keratoconjunctivitis (VKC)}

VKC is known as the disease of young males who live in warmer climates. ${ }^{[113,114]}$ Although VKC is frequently diagnosed in children, adults can also be affected with this condition. ${ }^{[115]} \mathrm{A}$ mixture of IgE and non-IgE reaction in response to nonspecific stimuli, such as wind, dust, and sunlight is often elucidated in this condition. Accordingly, skin tests and serum IgE antibody tests to well-known allergens are generally negative. ${ }^{[116]}$ Both clinical and histological findings support the concomitant role of T-helper 2 and $\operatorname{lgE}$ in the pathogenesis of VKC. ${ }^{[8,17]}$ Recently, IL-17 has been reported to be linked to VKC, where its serum levels can serve as a marker for the severity of the disease. ${ }^{[118,119]}$ High percentage of antinuclear antibodies (ANA) positivity and family history of autoimmune disorders in patients with VKC suggests a strong link between this condition and other autoimmune disorders including atopy. ${ }^{[120,121]}$

Typical seasonal patterns as well as perennial forms have been reported in patients affected with VKC. ${ }^{[122]}$ Presence of papillary hyperplasia is essential for the diagnosis of $\mathrm{VKC}$, and its presence allows for the differentiation of VKC from other related entities such as SAC and PAC. ${ }^{[123]}$

Conjunctival injection, profuse tearing, severe itching, and photophobia are the main clinical signs and symptoms that are associated with VKC. There are three clinical forms of VKC that include limbal, palpebral, and mixed type. ${ }^{[12]}$ Limbal type is characterized by limbal papillary reaction and gelatinous thickening of the limbus; when the disease is active, Horner-Trantas dots are usually present at the superior limbal margins. ${ }^{[112]}$ The hallmark of the palpebral VKC is the presence of giant papillae, with consequent cobblestone appearance. The mixed type has the features of palpebral and limbal VKC simultaneously (Figure 6).

The corneal pathology that is seen in VKC is partly caused by the mechanical trauma from the tarsal conjunctival papillae and the inflammatory responses secondary to the release of cytokines. The inflammatory mediators are believed to be released by the eosinophils and mast cells that are infiltrated into the conjunctival tissue. ${ }^{[124,125]}$ In up to $6 \%$ of patients, corneal ulcers (i.e., shields ulcer) and plaques may develop, leading to the exacerbation of the clinical symptoms and worsening of the vision. ${ }^{[126,127]}$ These ulcers are usually found as oval lesions with elevated margins surrounding a chronic epithelial defect covered by eosinophilic and epithelial debris in the upper parts of the cornea. ${ }^{[128]}$ Keratoconus is another entity that is highly associated with VKC affecting nearly $15 \%$ of the patients with this condition. ${ }^{[129]}$

\section{Atopic keratoconjunctivitis (AKC)}

AKC is characterized by chronic allergic disease of the eyelid, cornea, and conjunctiva. It is considered the ocular component of atopic dermatitis (AD), and roughly $95 \%$ of the patients with AKC have concomitant $A D ;\left[{ }^{[8,1]}\right.$ however, less than half of patients with $A D$ have involvement of their ocular tissue. ${ }^{[130]}$ Many cytokines are released from the epithelial cells of the conjunctiva as well as the inflammatory cells that have infiltrated the conjunctival tissues in AKC. This causes constant remodeling of the ocular surface connective tissue leading to mucus metaplasia, scar formation, and corneal neovascularization. ${ }^{[131]}$

AKC is typically diagnosed in the second and third decades of life, although scattered cases are seen in the early childhood as well as in the fifth 
decade of life. ${ }^{[132]}$ Age of the onset, duration of the disease, and clinical presentations may help clinicians to distinguish this condition from VKC. ${ }^{[32]}$

Clinical manifestation of AKC includes epiphora, itching, redness, and decreased vision. Presentation is often bilateral; however, unilateral disease has been reported. [133] The eyelid skin may be edematous with a sandpaper-like texture. Conjunctival injection and chemosis range from mild to severe, and conjunctival scarring is common. ${ }^{[11]}$ Trantas dots and giant papillae may or may not be present. In contrast to VKC, AKC is associated with conjunctival fibrosis and corneal vascularization and opacities. An early cataract surgery is not uncommon in AKC patients, as this condition is associated with formation of "atopic cataracts" at a relatively young age. Shield-like cataracts, as well as nuclear, cortical and even posterior subcapsular cataracts may also occur. Nearly $50 \%$ of AKC patients test negative for common allergens. ${ }^{[8]}$

\section{Giant papillary conjunctivitis (GPC)}

Similar to vernal conjunctivitis, GPC is characterized by papillary hypertrophy of the superior tarsal conjunctiva. ${ }^{[134]}$ Although GPC is primarily considered as a complication of contact lens usage, this condition has also been reported in association with corneal foreign bodies, filtering blebs, ocular prostheses, exposed sutures, limbal dermoids, and tissue adhesives. ${ }^{[135-137]}$ The classic signs of GPC consist of excessive mucous secretion associated with decreased contact lens tolerance. ${ }^{[137]}$ Mast cells and eosinophils may be found in the conjunctiva; however, there are no increases in the levels of $\lg \mathrm{E}$ or histamines in the tears of patients with GPC. ${ }^{[8]}$

GPC can occur with both hydrogel and rigid contact lenses, and it has been reported with either hydroxyethyl methacrylate (HEMA), silicone polymers, or the new gas permeable polymers. ${ }^{[134]}$ However, it is less frequent with rigid contact lenses. Mechanical injuries due to contact lens wear and inflammatory reactions secondary to surface proteins of the lens can contribute to the chronic inflammatory damage of the ocular surface ${ }^{[110,138]}$ seen in this condition.

\section{Contact allergy}

CDC is a classic example of type-IV delayed hypersensitivity reaction that occurs through interaction of antigens with $T$ cells followed by release of cytokines. ${ }^{[139]}$ Low molecular weight allergens combine with host proteins to form the final allergens capable of exerting immune response. Some of the known allergens for CDC include poison ivy, poison oak, neomycin, nickel, latex, atropine and its derivatives. ${ }^{[8]}$ Primary sensitization phase describes the process through which memory $T$ cells derive from resident $T$ cells of the ocular tissue, while the following elicitation phase includes the interaction between these memory cells and allergens. ${ }^{[8]} \mathrm{IL}-17$-producing Th cells and regulatory $T$ cells also play a role in the pathogenesis of CDC. ${ }^{[140]}$

Similar to AKC, contact allergy involves the conjunctiva, cornea, and eyelids. The condition may be associated with itching, lid swelling, follicular reaction, and even cicatrization in later stages of the disease. The corneal involvement may be in the form of punctate keratitis, pseudodendritic keratitis, and grayish stromal infiltrates. ${ }^{[112,141]}$

\section{Treatment}

Avoidance of the allergens is the main stay of treatment for many forms of allergies including allergic conjunctivitis. Artificial tears provide a barrier function, dilute various allergens, and flush the ocular surface clean from many inflammatory mediators.

The treatment options for allergic conjunctivitis include lubricating eye drops, anti-histamines, and mast cell stabilizers. ${ }^{[142,143]}$ Many studies have demonstrated the superiority of topical antihistamines and mast cell stabilizers compared to placebo in alleviating the symptoms of allergic conjunctivitis; in addition, it has been demonstrated that antihistamines are more beneficial than mast cell stabilizers for providing short-term relief. ${ }^{[144]}$ Several eye drop preparations with dual action (antihistamine and mast cellstabilizing effects) including olopatadine, ketotifen, azelastine, and epinastine have been introduced to market in the recent years. These agents can provide simultaneous histamine receptor antagonist effects, stabilize mast-cell membranes, 
and modify the action of eosinophils. ${ }^{[145]}$ Mast cell stabilizers require a loading period of several weeks, and therefore, they are better to be administered before the antigen exposure.

Oral antihistamines are commonly used for alleviating the ocular symptoms in patients with allergic conjunctivitis. Second generation antihistamines are preferred due to their fewer adverse systemic side effects. ${ }^{[146]}$ Unfortunately, oral antihistamines induce ocular drying, which can significantly worsen the symptoms of allergic conjunctivitis. ${ }^{[147]}$

Steroids should be used judiciously and only in selected cases. Topical and oral administration, in addition to supratarsal injections are often required if the condition is severe; unfortunately, any route of corticosteroid administration is associated with formation of cataracts and elevated intraocular pressure. ${ }^{[112]}$ Non-steroidal anti-inflammatory drugs such as ketorolac and diclofenac can also be added to the treatment regimen to provide additional benefits. Moreover, other steroid-sparing agents such as cyclosporine-A and tacrolimus are effective in treating severe and chronic forms of ocular allergies.

Allergen-specific immunotherapy, which has gained popularity in the recent years, works by inducing clinical tolerance to a specific allergen. This appears to be an effective treatment options for those with allergic rhinoconjunctivitis who demonstrate specific IgE antibodies. ${ }^{[148]}$ Traditionally, immunotherapy is performed via subcutaneous injections; however, sublingual immunotherapy (SLIT) has drawn the attention among allergists as an alternative. SLIT has been shown to effectively reduce the ocular and nasal signs and symptoms of allergic conjunctivitis, with a greater benefit toward improving the nasal symptoms. ${ }^{[112]}$

\section{Conjunctivitis associated with systemic diseases}

Conjunctivitis may be the initial presentation for many systemic diseases; therefore, a thorough history and systemic evaluation in selected cases may help in early diagnosis of many potentially disabling and even life-threatening conditions. A summary of systemic diseases associated with conjunctivitis is provided in Figure 7.

\section{Reactive arthritis}

Conjunctivitis is one of the most common ocular manifestations of reactive arthritis; other associated ocular entities include uveitis, episcleritis, scleritis, and keratitis. ${ }^{[149]}$ Conjunctivitis in reactive arthritis entities manifests itself as conjunctival hyperemia with purulent discharge. Occurring in nearly one third of the patients, conjunctivitis is an essential component of the "Reiter's triad". ${ }^{[150]}$ Conjunctivitis usually happens early in the course of reactive arthritis and it may even precede it in some instances; given its mild initial clinical presentation, it is often missed. The signs and symptoms usually abate within one to four weeks; however, in some cases, progression to more severe ocular surface problems may ensue. ${ }^{[151]}$

\section{Rosacea}

Ocular surface may also be involved in the inflammatory course of ocular rosacea. The clinical findings include a follicular and papillary conjunctival reaction in association with interpalpebral conjunctival hyperemia. In addition, cicatrization of the conjunctival tissue, mimicking trachoma, may be seen in these patients. Conjunctival scarring secondary to entropion and trichiasis has been reported to occur in approximately $10 \%$ of the cases. Conjunctival granuloma, pinguecula, phlyctenule, and peripheral corneal infiltration and phlyctenule are amongst some of the other findings associated with ocular rosacea. ${ }^{[152]}$

\section{Graft-versus-host disease}

Conjunctival involvement is rarely seen in acute graft-versus-host disease (GVHD); however, its presence indicates more severe systemic involvement and a poor prognosis. Conjunctival involvement in GVHD ranges from mild conjunctival injection to pseudomembranous and cicatrizing conjunctivitis. ${ }^{[153,154]}$ In acute GVHD, conjunctivitis is often ulcerative and manifests itself with numerous alternating episodes of conjunctival hemorrhage and 
exudative discharge. Sterile purulent discharge, pseudomembrane formation, and scarring are amongst the other findings in this condition. [153] In the chronic form of GVHD, one-fourth to three-fourth of the patients suffer from dry eyes, where its severity correlates with the severity of GVHD. ${ }^{[155]}$ Frequently, keratoconjunctivitis sicca persists after remission of GVHD. ${ }^{[156]}$

Four stages of conjunctival GVHD have been described in the literature. Stage 1 is marked by simple conjunctival injection. Stage 2 is characterized by an exudative response, which may lead to conjunctival chemosis. Stage 3 is characterized by pseudomembrane formation; majority of the patients are diagnosed at this stage of the diseases. Stage 4 is manifested by scarring and cicatrization of the conjunctival tissue. ${ }^{[153,156]}$

\section{Ocular cicatricial pemphigoid}

Ocular cicatricial pemphigoid is a rare condition. Patients are often in their fifth and sixth decades of life at presentation, and females are up to three times more frequently affected than males. ${ }^{[157]}$ Chronic inflammation, loss of conjunctival goblet cells along with an abnormal mucosal epithelial turn-over leads to desiccation of the ocular surface in this condition ${ }^{[158]}$ (Figure 8). Disruption of conjunctival immune network increases the risk of ocular surface infection. ${ }^{[158]}$ Recurrent infectious conjunctivitis and trichiasis may lead to keratinization of the surface epithelium. ${ }^{[158]}$ Definitive diagnosis requires direct immunofluorescence, where deposits of immunoglobulins and/or complements produce areas of linear hyperfluorescence at the epithelial basement membrane. Systemic immunosuppression along with frequent lubrication is often needed to adequately control this condition.

\section{Stevens-Johnson syndrome and toxic epidermal necrolysis}

Ophthalmic manifestations of the acute stages of Stevens-Johnson syndrome (SJS) and toxic epidermal necrolysis (TEN) range from conjunctival hyperemia to near-complete sloughing of palpebral conjunctiva and lid margins. ${ }^{[159]}$ Acute ocular involvement is reported to occur in up to $88 \%$ of the cases. ${ }^{[159]}$ It remains unclear whether the severity of ocular involvement is any different between SJS and TEN. ${ }^{[160]}$ Long-term adverse consequences following the acute stage of ocular surface disease include severe dry eyes, symblepharon formation, corneal limbal stem cell deficiency, and corneal scarring. ${ }^{[160]}$

\section{Toxic conjunctivitis}

It has been recently realized that long-term use of topical eye medications may induce ocular surface changes including dry eyes, conjunctival inflammation, ocular surface fibrosis, and scarring. ${ }^{[161,162]}$ Another area where the side effects of topical eye drops cause significant ocular morbidity is their use in glaucoma and in patients who have undergone glaucoma surgery. Subclinical infiltration of the conjunctival epithelium and substantia propria by inflammatory cells has also been reported. ${ }^{[163,164]}$ The published literature during the past decade has pointed to the deleterious effects of benzalkonium chloride (BAK), which is used as a preservative in eye drops, on the ocular surface. ${ }^{[165]}$

Allergic reactions are the most clinically noticeable side effect of the eye drops; however, they are far less frequent and harmful than their adverse toxic side effects. ${ }^{[166]}$ The allergic reaction to eye drops includes simple conjunctival congestion, papillary conjunctivitis, and GPC. ${ }^{[165]}$ The signs and symptoms usually manifest a few days after starting the offending eye drop and tend to resolve quickly when the medication is stopped. ${ }^{[166]}$

Observational studies have confirmed the high prevalence of dry eyes in glaucoma patients related to the number of eye drops being used. This ranges from $11 \%$ in those who use only one eye drop to $43 \%$ in those who use two or three different eye drops. ${ }^{[167]}$ Similarly, a cross-sectional study evaluating the ocular surface in 101 patients being treated for glaucoma reported that approximately $60 \%$ of them were symptomatic in at least one eye. ${ }^{[168]}$ In a survey performed on 300 patients in the US between 2001 and 2004, adverse side effects were reported to be the second most common reason for switching eye drops. ${ }^{[169]}$ 
Increase in fibroblast density in the conjunctiva, and development of subconjunctival fibrosis has been reported in patients who use antiglaucoma drops chronically. ${ }^{[165]}$ In a series of 145 patients, Thorne et al reported that exposure to antiglaucoma eye drops was the primary reason for development of pseudopemphigoid. ${ }^{[170]}$

Despite the indisputable data and the findings from multiple observational studies on the harmful side effects of BAK, it is still used as the main preservative ingredient in most eye drop preparations due to lack of a better alternative. ${ }^{[165]}$ Limiting the exposure to preservatives may diminish the toxic side effects of eye drops; this will likely lead to higher patient compliance and result in a more favorable clinical outcome, especially in those who need to be on antiglaucoma medications.

\section{Summary}

Approximately $1 \%$ of all patient visits to their primary care physician is conjunctivitis related, and the estimated cost of infectious conjunctivitis to the healthcare is more than $\$ 800$ million annually in the US alone. ${ }^{[2]}$ The first step in approaching a patient with presumed conjunctivitis is to rule out serious ocular conditions that present with "red eye", mimicking conjunctivitis. This must be done with obtaining a thorough history and performing a detailed ophthalmologic and physical examination. Ancillary laboratory testing and imaging are also important components of evaluating these patients. Various studies have demonstrated that obtaining a thorough history is essential to narrow down the differential diagnosis and discover the underlying etiology for the conjunctivitis, while relying solely on the presenting signs and symptoms can be misleading and often leads to an inaccurate diagnosis. Viral conjunctivitis followed by bacterial conjunctivitis are the most common causes of infectious conjunctivitis. ${ }^{[15,25,81]}$ The majority of viral conjunctivitis cases are due to adenoviruses, ${ }^{[28]}$ and the use of rapid antigen test to diagnose adenoviral conjunctivitis may present an appropriate strategy to avoid overuse of antibiotics. Bacterial pathogens are isolated in half of the cases of conjunctivitis, ${ }^{[61]}$ and approximately $60 \%$ of culture-positive cases are known to be self-limited. ${ }^{[80]}$ Cultures should be obtained from the conjunctival swabs of patients that do not respond to therapy, and those suspected to have chlamydial infection and hyperacute conjunctivitis. ${ }^{[4]}$ Treatment with topical antibiotics is usually recommended for suspected cases of chlamydial and gonococcal conjunctivitis and contact lens wearers. ${ }^{[61,80]}$ The majority of cases of allergic conjunctivitis are due to seasonal allergies. Antihistamines and mast cell stabilizers are widely used for treating allergic conjunctivitis. Steroids must be used judiciously and only when indicated. For patients with chronic conjunctivitis, possibility of systemic diseases and adverse effects of eye drops with preservatives should be kept in mind.

\section{REFERENCES}

1. Shekhawat NS, Shtein RM, Blachley TS, Stein JD. Antibiotic prescription fills for acute conjunctivitis among enrollees in a large United States managed care network. Ophthalmology 2017;124:1099-1107.

2. Smith AF, Waycaster $C$. Estimate of the direct and indirect annual cost of bacterial conjunctivitis in the United States. BMC Ophthalmol 2009;9:13.

3. Ryder EC, Benson S. Conjunctivitis. In: StatPearls. Treasure Island (FL): StatPearls Publishing LLC; 2020.

4. de Laet C, Dionisi-Vici C, Leonard JV, McKiernan P, Mitchell $G$, Monti $L$, et al. Recommendations for the management of tyrosinaemia type 1. Orphanet J Rare Dis 2013;8:8-8.

5. Sati A, Sangwan VS, Basu S. Porphyria: varied ocular manifestations and management. BMJ Case Rep 2013;2013:bcr2013009496.

6. Narayana S, McGee S. Bedside diagnosis of the 'Red Eye': a systematic review. Am J Med 2015;128:1220-1224.e1221.

7. Everitt $\mathrm{H}$, Little P. How do GPs diagnose and manage acute infective conjunctivitis? A GP survey. Fam Pract 2002;19:658-660.

8. La Rosa M, Lionetti E, Reibaldi $M$, et al. Allergic conjunctivitis: a comprehensive review of the literature. Ital J Pediatr 2013;39:18.

9. Friedlaender $\mathrm{MH}$. Ocular allergy. Curr Opin Allergy Clin Immunol 2011;11:477-482.

10. Bielory L, Frohman LP. Allergic and immunologic disorders of the eye. J Allergy Clin Immunol 1992;89:1-15.

11. Bielory B, Bielory L. Atopic dermatitis and keratoconjunctivitis. Immunol Allergy Clin North Am 2010;30:323-336.

12. Wilson-Holt N, Dart JK. Thiomersal keratoconjunctivitis, frequency, clinical spectrum and diagnosis. Eye 1989;3:581-587.

13. Soparkar CN, Wilhelmus KR, Koch DD, Wallace GW, Jones DB. Acute and chronic conjunctivitis due to overthe-counter ophthalmic decongestants. Arch Ophthalmol 1997;115:34-38.

14. van Ketel WG, Melzer-van Riemsdijk FA. Conjunctivitis due to soft lens solutions. Contact Dermatitis 1980;6:321-324. 
15. Woodland RM, Darougar S, Thaker U, Cornell L, Siddique M, Wania J, et al. Causes of conjunctivitis and keratoconjunctivitis in Karachi, Pakistan. Trans Royal Soc Trop Med Hygiene 1992;86:317-320.

16. Bielory BP, O'Brien TP, Bielory L. Management of seasonal allergic conjunctivitis: guide to therapy. Acta Ophthalmologica 2012;90:399-407.

17. Rietveld RP, van Weert $\mathrm{HC}$, ter Riet G, Bindels PJ. Diagnostic impact of signs and symptoms in acute infectious conjunctivitis: systematic literature search. $B M J$ 2003;327:789.

18. Rietveld RP, ter Riet G, Bindels PJ, Sloos JH, van Weert $\mathrm{HC}$. Predicting bacterial cause in infectious conjunctivitis: cohort study on informativeness of combinations of signs and symptoms. BMJ 2004;329:206-210.

19. Jefferis J, Perera R, Everitt $H$, van Weert $H$, Rietveld R, Glasziou $P$, et al. Acute infective conjunctivitis in primary care: who needs antibiotics? An individual patient data meta-analysis. Br J Gen Pract 2011;61:e542-548.

20. van Weert HC, Tellegen E, Ter Riet G. A new diagnostic index for bacterial conjunctivitis in primary care. A rederivation study. Eur J Gen Pract 2014;20:202-208.

21. Azari AA, Barney NP. Conjunctivitis: a systematic review of diagnosis and treatment. JAMA 2013;310:1721-1729.

22. Drew RJ, Cole TS, Newman W. How to use... eye swabs. Arch Dis Child Educ Pract Ed 2015;100:155-161.

23. Wong VW, Lai TY, Chi SC, Lam DS. Pediatric ocular surface infections: a 5-year review of demographics, clinical features, risk factors, microbiological results, and treatment. Cornea 2011;30:995-1002.

24. Kam KY, Ong HS, Bunce C, Ogunbowale L, Verma S. Sensitivity and specificity of the AdenoPlus point-of-care system in detecting adenovirus in conjunctivitis patients at an ophthalmic emergency department: a diagnostic accuracy study. Br J Ophthalmol 2015;99:1186-1189.

25. Stenson S, Newman R, Fedukowicz H. Laboratory studies in acute conjunctivitis. Arch Ophthalmology 1982;100:1275-1277.

26. Fitch CP, Rapoza PA, Owens S, Murillo-Lopez F, Johnson RA, Quinn TC, et al. Epidemiology and diagnosis of acute conjunctivitis at an inner-city hospital. Ophthalmology 1989;96:1215-1220.

27. Newman H, Gooding C. Viral ocular manifestations: a broad overview. Rev Med Virol 2013;23:281-294.

28. O'Brien TP, Jeng BH, McDonald M, Raizman MB. Acute conjunctivitis: truth and misconceptions. Curr Med Res Opin 2009;25:1953-1961.

29. Singh G, Zhou X, Lee JY, Yousuf MA, Ramke M, Ismail $A M$, et al. Recombination of the epsilon determinant and corneal tropism: human adenovirus species D types 15, 29, 56, and 69. Virology 2015;485:452-459.

30. Kuo IC. Adenoviral keratoconjunctivitis: diagnosis, management, and prevention. Curr Ophthalmol Rep 2019;7:118-127.

31. Li J, Lu X, Sun Y, Lin C, Li F, Yang Y, et al. A swimming pool-associated outbreak of pharyngoconjunctival fever caused by human adenovirus type 4 in Beijing, China. Int J Infect Dis 2018;75:89-91.

32. Harley D, Harrower B, Lyon M, Dick A. A primary school outbreak of pharyngoconjunctival fever caused by adenovirus type 3. Comm Dis Intell 2001;25:9-12.
33. Sinclair RG, Jones EL, Gerba CP. Viruses in recreational water-borne disease outbreaks: a review. J Appl Microbiol 2009;107:1769-1780.

34. Darougar S, Grey RH, Thaker U, McSwiggan DA. Clinical and epidemiological features of adenovirus keratoconjunctivitis in London. Br J Ophthalmo/ 1983;67:17.

35. Jhanji V, Chan TC, Li EY, Agarwal K, Vajpayee RB. Adenoviral keratoconjunctivitis. Surv Ophthalmol 2015;60:435-443.

36. Chintakuntlawar AV, Chodosh J. Cellular and tissue architecture of conjunctival membranes in epidemic keratoconjunctivitis. Ocul Immunol Inflamm 2010;18:341345.

37. Chigbu DI, Labib BA. Pathogenesis and management of adenoviral keratoconjunctivitis. Infect Drug Resist 2018;11:981-993.

38. Richmond S, Burman R, Crosdale E, et al. A large outbreak of keratoconjunctivitis due to adenovirus type 8 . The Journal of hygiene 1984;93:285-291.

39. Okumus S, Coskun E, Tatar MG, Kaydu E, Yayuspayi R, Comez A, et al. Cyclosporine a 0.05\% eye drops for the treatment of subepithelial infiltrates after epidemic keratoconjunctivitis. BMC Ophthalmol 2012;12:42.

40. Ghanem RC, Vargas JF, Ghanem VC. Tacrolimus for the treatment of subepithelial infiltrates resistant to topical steroids after adenoviral keratoconjunctivitis. Cornea 2014;33:1210-1213.

41. Gallenga PE, Lobefalo L, Colangelo L, Della Loggia G, Orzalesi N, Velati $P$, et al. Topical lomefloxacin $0.3 \%$ twice daily versus tobramycin $0.3 \%$ in acute bacterial conjunctivitis: a multicenter double-blind phase III study. Ophthalmologica 1999;213:250-257.

42. Udeh BL, Schneider JE, Ohsfeldt RL. Cost effectiveness of a point-of-care test for adenoviral conjunctivitis. Am J Med Sci 2008;336:254-264.

43. Jackson WB, Low DE, Dattani D, Whitsitt PF, Leeder RG, MacDougall R. Treatment of acute bacterial conjunctivitis: $1 \%$ fusidic acid viscous drops vs. $0.3 \%$ tobramycin drops. Can J Ophthalmol 2002;37:228-237; discussion 237.

44. Gordon YJ, Gordon RY, Romanowski E, Araullo-Cruz TP. Prolonged recovery of desiccated adenoviral serotypes 5,8 , and 19 from plastic and metal surfaces in vitro. Ophthalmology 1993;100:1835-1839; discussion 18391840.

45. Junk AK, Chen PP, Lin SC, Nouri-Mahdavi K, Radhakrishnan S, Singh $K$, et al. Disinfection of Tonometers: a report by the American Academy of Ophthalmology. Ophthalmology 2017;124:1867-1875.

46. Bremond-Gignac D, Mariani-Kurkdjian P, Beresniak A, El Fekih L, Bhagat Y, Pouliquen P, et al. Efficacy and safety of azithromycin $1.5 \%$ eye drops for purulent bacterial conjunctivitis in pediatric patients. Pediatr Infect Dis $J$ 2010;29:222-226.

47. Varu DM, Rhee MK, Akpek EK, Amescua G, Farid M, Garcia-Ferrer FJ, et al. Conjunctivitis preferred practice pattern ${ }^{\circledR}$. Ophthalmology 2019;126:P94-P169.

48. Leibowitz HM. Antibacterial effectiveness of ciprofloxacin $0.3 \%$ ophthalmic solution in the treatment of bacterial conjunctivitis. Am J Ophthalmol 1991;112:29s-33s. 
49. Trinavarat A, Atchaneeyasakul LO. Treatment of epidemic keratoconjunctivitis with $2 \%$ povidone-iodine: a pilot study. J Ocul Pharmacol Ther 2012;28:53-58.

50. Kovalyuk N, Kaiserman I, Mimouni M, Cohen O, Levartovsky S, Sherbany $\mathrm{H}$, et al. Treatment of adenoviral keratoconjunctivitis with a combination of povidone-iodine $1.0 \%$ and dexamethasone $0.1 \%$ drops: a clinical prospective controlled randomized study. Acta Ophthalmol 2017;95:e686-e692.

51. Holland EJ, Bartlett JD, Paterno MR, Usner DW, Comstock TL. Effects of loteprednol/tobramycin versus dexamethasone/tobramycin on intraocular pressure in healthy volunteers. Cornea 2008;27:50-55.

52. Belfort R, Jr., Gabriel L, Martins Bispo PJ, Muccioli C, Zacharias Serapicos PC, Clark L, et al. Safety and efficacy of moxifloxacin-dexamethasone eyedrops as treatment for bacterial ocular infection associated with bacterial blepharitis. Adv Ther 2012;29:416-426.

53. Clement C, Capriotti JA, Kumar M, et al. Clinical and antiviral efficacy of an ophthalmic formulation of dexamethasone povidone-iodine in a rabbit model of adenoviral keratoconjunctivitis. Investigative ophthalmology \& visual science 2011;52:339-344.

54. Pinto RD, Lira RP, Abe RY, Fernandes Felix JP, Fernandes Pereira AV, Leite Arieta CE, et al. Dexamethasone/povidone eye drops versus artificial tears for treatment of presumed viral conjunctivitis: a randomized clinical trial. Curr Eye Res 2015;40:870-877.

55. Pepose JS, Ahuja A, Liu W, Narvekar A, Haque R. Randomized, controlled, phase 2 trial of povidoneiodine/dexamethasone ophthalmic suspension for treatment of adenoviral conjunctivitis. Am J Ophthalmol 2019;205:197.

56. Levinger E, Slomovic A, Sansanayudh W, Bahar I, Slomovic AR. Topical treatment with $1 \%$ cyclosporine for subepithelial infiltrates secondary to adenoviral keratoconjunctivitis. Cornea 2010;29:638-640.

57. Jeng $\mathrm{BH}$, Holsclaw DS. Cyclosporine A $1 \%$ eye drops for the treatment of subepithelial infiltrates after adenoviral keratoconjunctivitis. Cornea 2011;30:958-961.

58. Reinhard T, Godehardt E, Pfahl HG, Sundmacher R. [Local cyclosporin A in nummuli after keratoconjunctivitis epidemica. a pilot study]. Ophthalmologe 2000;97:764768.

59. Hillenkamp J, Reinhard T, Ross RS, Böhringer D, Cartsburg $\mathrm{O}$, Roggendorf $\mathrm{M}$, et al. Topical treatment of acute adenoviral keratoconjunctivitis with $0.2 \%$ cidofovir and $1 \%$ cyclosporine: a controlled clinical pilot study. Arch Ophthal 2001;119:1487-1491.

60. Berisa Prado S, Riestra Ayora AC, Lisa Fernandez C, Chacon Rodriguez M, Merayo-Lloves J, Alfonso Sanchez JF. Topical tacrolimus for corneal subepithelial infiltrates secondary to adenoviral keratoconjunctivitis. Cornea 2017;36:1102-1105.

61. Cronau H, Kankanala RR, Mauger T. Diagnosis and management of red eye in primary care. Am Fam Phys 2010;81:137-144.

62. Sheikh A, Hurwitz B, van Schayck CP, McLean S, Nurmatov $U$. Antibiotics versus placebo for acute bacterial conjunctivitis. Cochrane Database Syst Rev 2012;19:Cd001211.
63. Papa V, Aragona P, Scuderi AC, Blanco AR, Zola P, Alessandro $\mathrm{Di} \mathrm{B}$, et al. Treatment of acute bacterial conjunctivitis with topical netilmicin. Cornea 2002;21:4347.

64. Puri LR, Shrestha GB, Shah DN, Chaudhary M, Thakur A. Ocular manifestations in herpes zoster ophthalmicus. Nepal J Ophthalmol 2011;3:165-171.

65. Sy A, McLeod SD, Cohen EJ, Margolis TP, Mannis MJ, Lietman TM, et al. Practice patterns and opinions in the management of recurrent or chronic herpes zoster ophthalmicus. Cornea 2012;31:786-790.

66. Lim KH, Yin-Murphy $M$. Epidemic conjunctivitis in Singapore in 1970 and 1971. Singapore Med J 1973;14:8689.

67. Kono R, Sasagawa A, Miyamura K, Tajiri E. Serologic characterization and sero-epidemiologic studies on acute hemorrhagic conjunctivitis (AHC) virus. Am J Epidemiol 1975;101:444-457.

68. Zhang L, Zhao N, Huang X, Jin X, Geng X, Chan T$C$, et al. Molecular epidemiology of acute hemorrhagic conjunctivitis caused by coxsackie a type 24 variant in China, 2004-2014. Sci Rep 2017;7:45202.

69. Langford MP, Anders EA, Burch MA. Acute hemorrhagic conjunctivitis: anti-coxsackievirus A24 variant secretory immunoglobulin $A$ in acute and convalescent tear. Clin Ophthalmol 2015;9:1665-1673.

70. Serin S, Bozkurt Oflaz A, Karabagli P, Gedik S, Bozkurt B. Eyelid molluscum contagiosum lesions in two patients with unilateral chronic conjunctivitis. Turk $J$ Ophthalmol 2017;47:226-230.

71. Breman JG, Heymann DL, Lloyd G, McCormick JB, Miatudila M, Murphy FA, et al. Discovery and description of ebola zaire virus in 1976 and relevance to the West African epidemic during 2013-2016. J Infect Dis 2016;214:S93S101.

72. Moshirfar M, Fenzl CR, Li Z. What we know about ocular manifestations of Ebola. Clin Ophthalmol 2014;8:23552357.

73. Bausch DG, Schwarz L. Outbreak of ebola virus disease in Guinea: where ecology meets economy. PLoS Negl Trop Dis 2014;8:e3056-e3056.

74. Peiris JS, Lai ST, Poon LL, Guan Y, Yam LYC, Lim W, et al. Coronavirus as a possible cause of severe acute respiratory syndrome. Lancet 2003;361:1319-1325.

75. Huang C, Wang Y, Li X, Ren L, Zhao J, Hu Y, et al. Clinical features of patients infected with 2019 novel coronavirus in Wuhan, China. Lancet 2020;395:P497-P506.

76. Karimi S, Arabi A, Shahraki T, Safi S. Detection of severe acute respiratory syndrome Coronavirus- 2 in the tears of patients with Coronavirus disease 2019. Eye. Retrieved from: https://doi.org/10.1038/s41433-020-0965-2.

77. Epling J. Bacterial conjunctivitis. BMJ Clin Evid 2012;2012:0704.

78. Shields T, Sloane PD. A comparison of eye problems in primary care and ophthalmology practices. Fam Med 1991;23:544-546.

79. Karpecki P, Depaolis M, Hunter JA, White EM, Rigel L, Brunner LS, et al. Besifloxacin ophthalmic suspension $0.6 \%$ in patients with bacterial conjunctivitis: A multicenter, prospective, randomized, double-masked, vehiclecontrolled, 5-day efficacy and safety study. Clin Ther 2009;31:514-526. 
80. Hovding G. Acute bacterial conjunctivitis. Acta 96 Ophthalmol 2008;86:5-17.

81. Horven I. Acute conjunctivitis. A comparison of fusidic acid viscous eye drops and chloramphenicol. Acta Ophthalmol 1993;71:165-168.

82. Wall AR, Sinclair N, Adenis JP. Comparison of fucithalmic (fusidic acid viscous eyedrops 1\%) and noroxin (norfloxacin ophthalmic solution $0.3 \%$ ) in the treatment of acute bacterial conjunctivitis. J Drug Assess 1998;1:549-558.

83. Rose PW, Harnden A, Brueggemann AB, Perera R, Sheikh $A$, Crook D, et al. Chloramphenicol treatment for acute infective conjunctivitis in children in primary care: a randomised double-blind placebo-controlled trial. Lancet 2005;366:37-43.

84. Schiebel NE. Evidence-based emergency medicine/systematic review abstract. Use of antibiotics in patients with acute bacterial conjunctivitis. Ann Emer Med 2003;41:407-409.

85. Gong L, Sun XH, Qiu XD, Zhang Y-Q, Qu J, Yuan ZI, et al. [Comparative research of the efficacy of the gatifloxacin and levofloxacin for bacterial conjunctivitis in human eyes]. [Zhonghua yan ke za zhi] Chinese $J$ Ophthalmol 2010;46:525-531.

86. Tepedino ME, Heller WH, Usner DW, Brunner LS, Morris TW, Haas W, et al. Phase III efficacy and safety study of besifloxacin ophthalmic suspension $0.6 \%$ in the treatment of bacterial conjunctivitis. Curr Med Res Opin 2009;25:1159-1169.

87. Hwang DG, Schanzlin DJ, Rotberg MH, Foulks G, Raizman MB. A phase III, placebo controlled clinical trial of $0.5 \%$ levofloxacin ophthalmic solution for the treatment of bacterial conjunctivitis. Br J Ophthalmol 2003;87:10041009.

88. Shanmuganathan VA, Armstrong M, Buller A, Tullo AB. External ocular infections due to methicillin-resistant Staphylococcus aureus (MRSA). Eye 2005;19:284-291.

89. Zhang $\mathrm{M}, \mathrm{Hu} \mathrm{Y}$, Chen $\mathrm{F}$. [Clinical investigation of $0.3 \%$ levofloxacin eyedrops on the treatment of cases with acute bacterial conjunctivitis and bacterial keratitis]. Yan Ke Xue Bao [Eye Sci] 2000;16:146-148.

90. Gross RD, Lichtenstein S, Schlech BA, Gower LA, Potts SL. Early clinical and microbiological responses in the treatment of bacterial conjunctivitis with moxifloxacin ophthalmic solution $0.5 \%$ (Vigamox ${ }^{T M}$ ) using B.I.D. dosing. Today Ther Trends 2003;21:227-237.

91. Thareja T, Kowalski R, Jhanji V, Kamyar R, Dhaliwal D. MRSA keratitis and conjunctivitis: what does it mean practically? Curr Ophthalmol Rep 2019;7:110-117.

92. Burton MJ. Trachoma: an overview. Br Med Bull 2007;84:99-116.

93. Granet DB, Dorfman M, Stroman D, Cockrum P. A multicenter comparison of polymyxin B sulfate/trimethoprim ophthalmic solution and moxifloxacin in the speed of clinical efficacy for the treatment of bacterial conjunctivitis. J Pediatr Ophthalmol Strabismus 2008;45:340-349.

94. Leibowitz HM. The red eye. New Engl J Med 2000;343:345-351.

95. Tabbara KF, El-Sheikh HF, Islam SM, Hammouda E. Treatment of acute bacterial conjunctivitis with topical lomefloxacin $0.3 \%$ compared to topical ofloxacin 0.3\%. Eur J Ophthalmol 1999;9:269-275.
96. Abelson MB, Heller W, Shapiro AM, Si E, Hsu P, Bowman LM. Clinical cure of bacterial conjunctivitis with azithromycin 1\%: vehicle-controlled, double-masked clinical trial. Am J Ophthalmol 2008;145:959-965.

97. Cochereau I, Meddeb-Ouertani A, Khairallah M, Amraoui A, Zaghloul K, Pop M, et al. 3-day treatment with azithromycin $1.5 \%$ eye drops versus 7-day treatment with tobramycin $0.3 \%$ for purulent bacterial conjunctivitis: multicentre, randomised and controlled trial in adults and children. Br J Ophthalmol 2007;91:465-469.

98. Darville T. Chlamydia trachomatis infections in neonates and young children. Semin Pediatr Infect Dis 2005;16:235-244.

99. Mallika P, Asok T, Faisal H, Aziz S, Tan A, Intan G. Neonatal conjunctivitis - a review. Malays Fam Phys 2008;3:77-81.

100. Castro Ochoa KJ, Mendez MD. Ophthalmia Neonatorum. In: StatPearls. Treasure Island (FL): StatPearls Publishing LLC; 2020.

101. Forster RK, Dawson CR, Schachter J. Late follow-up of patients with neonatal inclusion conjunctivitis. $A m \mathrm{~J}$ Ophthalmol 1970;69:467-472.

102. Tipple MA, Beem MO, Saxon EM. Clinical characteristics of the afebrile pneumonia associated with Chlamydia trachomatis infection in infants less than 6 months of age. Pediatrics 1979;63:192-197.

103. Zikic A, Schunemann $H$, Wi T, Lincetto O, Broutet $\mathrm{N}$, Santesso N. Treatment of neonatal chlamydial conjunctivitis: a systematic review and meta-analysis. J Pediatr Infect Dis Soc 2018;7:e107-e115.

104. Hammerschlag MR, Gelling M, Roblin PM, Kutlin A, Jule JE. Treatment of neonatal chlamydial conjunctivitis with azithromycin. Pediatr Infect Dis J 1998;17:1049-1050.

105. Srivastava K, Arora A, Kataria A, Cappelleri JC, Sadosky A, Peterson AM. Impact of reducing dosing frequency on adherence to oral therapies: a literature review and metaanalysis. Patient Prefer Adherence 2013;7:419-434.

106. Costumbrado J, Ng DK, Ghassemzadeh S. Gonococcal conjunctivitis. In: StatPearls. Treasure Island (FL): StatPearls Publishing; 2020.

107. Hammerschlag MR, Smith-Norowitz T, Kohlhoff SA. Keeping an eye on Chlamydia and gonorrhea conjunctivitis in infants in the United States, 2010-2015. Sex Transm Dis 2017;44:577.

108. Pak KY, Kim SI, Lee JS. Neonatal bacterial conjunctivitis in Korea in the 21st century. Cornea 2017;36:415-418.

109. Leonardi A, De Dominicis C, Motterle L. Immunopathogenesis of ocular allergy: a schematic approach to different clinical entities. Curr Opin Allergy Clin Immunol 2007;7:429-435.

110. Wong $\mathrm{AH}$, Barg SS, Leung AK. Seasonal and perennial allergic conjunctivitis. Recent Pat Inflamm Allergy Drug Discov 2014;8:139-153.

111. Bonini S. Atopic keratoconjunctivitis. Allergy 2004;59:7173.

112. Rathi VM, Murthy SI. Allergic conjunctivitis. Commun Eye Health 2017;30:S7-S10.

113. Sofi RA, Mufti A. Vernal keratoconjunctivitis in Kashmir: a temperate zone. Int Ophthalmol 2016;36:875-879.

114. Katelaris $\mathrm{CH}$. Ocular allergy in the Asia Pacific region. Asia Pac Allergy 2011;1:108-114. 
115. De Smedt S, Wildner G, Kestelyn P. Vernal keratoconjunctivitis: an update. $\mathrm{Br} J$ Ophthalmol 2013;97:9-14.

116. Jun J, Bielory L, Raizman MB. Vernal conjunctivitis. Immunol Allergy Clin North Am 2008;28:59-82, vi.

117. Zicari AM, Capata G, Nebbioso M, De Castro G, Midulla $F$, Leonardi $L$, et al. Vernal keratoconjunctivitis: an update focused on clinical grading system. Ital J Pediatr 2019;45:64.

118. Zicari AM, Nebbioso M, Zicari A, Mari E, Celani C, Occasi $F$, et al. Serum levels of IL-17 in patients with vernal keratoconjunctivitis: a preliminary report. Eur Rev Med Pharmacol Sci 2013;17:1242-1244.

119. Validad MH, Khazaei HA, Pishjoo M, Safdari Z. The study of Interleukin-17 level in vernal keratoconjunctivitis disease and its relationship between symptom and sign severity. Sem Ophthalmol 2017;32:721-724.

120. Occasi F, Zicari AM, Petrarca L, Nebbioso M, Salvatori $G$, Duse M. Vernal keratoconjunctivitis and immunemediated diseases: one unique way to symptom control? Pediatr Allergy Immunol 2015;26:289-291.

121. Zicari AM, Nebbioso M, Lollobrigida $V$, Bardanzellu F, Celani C, Occasi F, et al. Vernal keratoconjunctivitis: atopy and autoimmunity. Eur Rev Med Pharmacol Sci 2013;17:1419-1423.

122. Singhal D, Sahay P, Maharana PK, Raj N, Sharma N, Titiyal JS. Vernal keratoconjunctivitis. Surv Ophthalmol 2019;64:289-311.

123. Pucci N, Novembre E, Lombardi E, Cianferoni A, Bernardini R, Massai C, et al. Atopy and serum eosinophil cationic protein in 110 white children with vernal keratoconjunctivitis: differences between tarsal and limbal forms. Clin Exp Allergy 2003;33:325-330.

124. Kumagai N, Fukuda K, Fujitsu Y, Yamamoto K, Nishida T. Role of structural cells of the cornea and conjunctiva in the pathogenesis of vernal keratoconjunctivitis. Prog Retin Eye Res 2006;25:165-187.

125. Leonardi A, Bogacka E, Fauquert JL, Kowalski ML, Groblewska A, Jedrzejczak-Czechowicz M, et al. Ocular allergy: recognizing and diagnosing hypersensitivity disorders of the ocular surface. Allergy 2012;67:13271337.

126. Solomon A. Corneal complications of vernal keratoconjunctivitis. Curr Opin Allergy Clin Immunol 2015;15:489-494.

127. Cameron JA, Mullaney PB. Amblyopia resulting from shield ulcers and plaques of the cornea in vernal keratoconjunctivitis. J Pediatr Ophthalmol Strabismus 1997;34:261-262.

128. Cameron JA. Shield ulcers and plaques of the cornea in vernal keratoconjunctivitis. Ophthalmology 1995;102:985-993.

129. Totan Y, Hepsen IF, Cekic O, Gunduz A, Aydin E. Incidence of keratoconus in subjects with vernal keratoconjunctivitis: a videokeratographic study. Ophthalmology 2001;108:824-827.

130. Guglielmetti S, Dart JK, Calder V. Atopic keratoconjunctivitis and atopic dermatitis. Curr Opin Allergy Clin Immunol 2010;10:478-485.

131. Offiah I, Calder VL. Immune mechanisms in allergic eye diseases: what is new? Curr Opin Allergy Clin Immunol 2009;9:477-481.
132. Chen JJ, Applebaum DS, Sun GS, Pflugfelder SC. Atopic keratoconjunctivitis: a review. J Am Acad Dermatol 2014;70:569-575.

133. Li A, Li S, Ruan F, Jie Y. Atopic keratoconjunctivitis: a diagnostic dilemma-a case report. Medicine 2018;97:e0372.

134. Elhers WH, Donshik PC. Giant papillary conjunctivitis. Curr Opin Allergy Clin Immunol 2008;8:445-449.

135. Forister JF, Forister EF, Yeung KK, Ye P, Chung MY, Tsui $A$, et al. Prevalence of contact lens-related complications: UCLA contact lens study. Eye Contact Lens 2009;35:176180.

136. Vengayil S, Vanathi M, Dada T, Kai S, Panda A. Filtering bleb-induced giant papillary conjunctivitis. Cont Lens Anterior Eye 2008;31:41-43.

137. Elhers W, Donshik P. Giant papillary conjunctivitis. Curr Opin Allergy Clin Immunol 2008;8:445-449.

138. Donshik PC, Ehlers WH, Ballow M. Giant papillary conjunctivitis. Immunol Allergy Clin North Am 2008;28:83-103, vi.

139. Niederkorn JY. Immune regulatory mechanisms in allergic conjunctivitis: insights from mouse models. Curr Opin Allergy Clin Immunol 2008;8:472-476.

140. Oboki K, Ohno T, Saito H, Nakae S. Th17 and allergy. Allergol Int 2008;57:121-134.

141. Dart J. Corneal toxicity: the epithelium and stroma in iatrogenic and factitious disease. Eye 2003;17:886-892.

142. Schmid KL, Schmid LM. Ocular allergy: causes and therapeutic options. Clin Exp Optom 2000;83:257-270.

143. Gokhale NS. Systematic approach to managing vernal keratoconjunctivitis in clinical practice: Severity grading system and a treatment algorithm. Indian J Ophthalmol 2016;64:145-148.

144. Owen CG, Shah A, Henshaw K, Smeeth L, Sheikh A. Topical treatments for seasonal allergic conjunctivitis: systematic review and meta-analysis of efficacy and effectiveness. Br J Gen Pract 2004;54:451-456.

145. Mishra GP, Tamboli V, Jwala J, Mitra AK. Recent patents and emerging therapeutics in the treatment of allergic conjunctivitis. Recent Pat Inflamm Allergy Drug Discov 2011;5:26-36.

146. Maziak W, Behrens T, Brasky TM, Duhme H, Rzehak P Weiland SK, et al. Are asthma and allergies in children and adolescents increasing? Results from ISAAC phase I and phase III surveys in Munster, Germany. Allergy 2003;58:572-579.

147. Welch D, Ousler GW, 3rd, Nally LA, Abelson MB, Wilcox $\mathrm{KA}$. Ocular drying associated with oral antihistamines (loratadine) in the normal population-an evaluation of exaggerated dose effect. Adv Exp Med Biol 2002;506:1051-1055.

148. Broide $\mathrm{DH}$. Immunomodulation of allergic disease. Ann Rev Med 2009;60:279-291.

149. Szamocki S, Martyn-Hemphill C, Green J. Reactive arthritis: can't see, can't pee, can't climb a tree.... Trends Urol Men Health 2016;7:17-20.

150. Keat A. Reiter's syndrome and reactive arthritis in perspective. New Engl J Med 1983;309:1606-1615.

151. Hamdulay SS, Glynne SJ, Keat A. When is arthritis reactive? Postgrad Med J 2006;82:446-453. 
152. Faraj HG, Hoang-Xuan T. Chronic cicatrizing 161 conjunctivitis. Curr Opin Ophthalmol 2001;12:250-257.

153. Jabs DA, Wingard J, Green WR, Farmer ER, Vogelsang $\mathrm{G}$, Saral R. The eye in bone marrow transplantation. III. Conjunctival graft-vs-host disease. Arch Ophthalmol 1989;107:1343-1348.

154. Azari A, Rezaei Kanavi M, Potter H, Hematti P. Autologous serum eye drop is safe and effective for treatment of dry eyes in graft-versus-host disease. Invest Ophthalmol Vis Sci 2013;54:4330-4330.

155. Tabbara KF, Al-Ghamdi A, Al-Mohareb F, Ayas M, Chaudhri N, Al-ShariF f, et al. Ocular findings after allogeneic hematopoietic stem cell transplantation. Ophthalmology 2009;116:1624-1629.

156. Nassar A, Tabbara KF, Aljurf M. Ocular manifestations of graft-versus-host disease. Saudi J Ophthalmol 2013;27:215-222.

157. Bedell AJ. Ocular pemphigus: a clinical presentation of kodachromes. Trans Am Ophthalmol Soc 1964;62:109_ 122.

158. Wang K, Seitzman G, Gonzales JA. Ocular cicatricial pemphigoid. Curr Opin Ophthalmol 2018;29:543-551.

159. Kohanim S, Palioura S, Saeed HN, et al. Acute and chronic ophthalmic involvement in Stevens-Johnson syndrome/toxic epidermal necrolysis - a comprehensive review and guide to therapy. II. Ophthalmic disease. Ocul Surf 2016;14:168-188.

160. Chow LLW, Shih KC, Chan JCY, Lai JSM, Ng ALK. Comparison of the acute ocular manifestations of StevensJohnson syndrome and toxic epidermal necrolysis in Chinese eyes: a 15-year retrospective study. BMC Ophthalmol 2017;17:65.
Broadway D, Grierson I, Hitchings R. Adverse effects of topical antiglaucomatous medications on the conjunctiva. Br J Ophthalmol 1993;77:590-596.

162. Schwab IR, Linberg JV, Gioia VM, Benson WH, Chao GM. Foreshortening of the inferior conjunctival fornix associated with chronic glaucoma medications. Ophthalmology 1992;99:197-202.

163. Mietz $H$, Niesen $U$, Krieglstein GK. The effect of preservatives and antiglaucomatous medication on the histopathology of the conjunctiva. Graefes Arch Clin Exp Ophthalmol 1994;232:561-565.

164. Baudouin C, Pisella PJ, Fillacier K, et al. Ocular surface inflammatory changes induced by topical antiglaucoma drugs: human and animal studies. Ophthalmology 1999;106:556-563.

165. Baudouin C, Labbe A, Liang H, Pauly A, BrignoleBaudouin F. Preservatives in eyedrops: the good, the bad and the ugly. Prog Retin Eye Res 2010;29:312-334.

166. Baudouin C. Allergic reaction to topical eyedrops. Curr Opin Allergy Clin Immunol 2005;5:459-463.

167. Rossi GC, Tinelli C, Pasinetti GM, Milano G, Bianchi PE. Dry eye syndrome-related quality of life in glaucoma patients. Eur J Ophthalmol 2009;19:572-579.

168. Leung EW, Medeiros FA, Weinreb RN. Prevalence of ocular surface disease in glaucoma patients. J Glaucoma 2008;17:350-355.

169. Zimmerman TJ, Hahn SR, Gelb L, Tan H, Kim EE. The impact of ocular adverse effects in patients treated with topical prostaglandin analogs: changes in prescription patterns and patient persistence. J Ocul Pharmacol Ther 2009;25:145-152.

170. Thorne JE, Anhalt GJ, Jabs DA. Mucous membrane pemphigoid and pseudopemphigoid. Ophthalmology 2004;111:45-52. 